\title{
Breaking the low pay, no pay cycle: the effects of the UK Employment Retention and Advancement programme
}

\author{
Richard Hendra ${ }^{*}$, James Riccio ${ }^{1}$, Richard Dorsett ${ }^{2}$ and Philip K. Robins ${ }^{3}$
}

\author{
* Correspondence: \\ Richard.Hendra@mdrc.org \\ ${ }^{1}$ MDRC, New York, USA \\ Full list of author information is \\ available at the end of the article
}

\begin{abstract}
This paper presents the final economic results of the UK Employment Retention and Advancement (ERA) programme. ERA's distinctive combination of post-employment advisory support and financial incentives was designed to help low-income individuals who entered work sustain employment and advance in the labour market. ERA targeted three groups. ERA produced short-term earnings gains for two lone parent target groups. However, these effects generally faded after the programme ended, largely because the control group caught up with the ERA group. For the New Deal 25 Plus target group (mostly long term unemployed men), ERA produced modest but sustained increases in employment and earnings.
\end{abstract}

JEL Codes: $138, \mathrm{J18}, \mathrm{C} 93$

Keywords: Financial incentives; Welfare-to-work; Long term unemployed; Field experiment

\section{Introduction}

This paper presents the final results on the implementation, impacts, costs, and economic benefits of the UK Employment Retention and Advancement (ERA) programme, which sought to improve the labour market prospects of low-paid workers and long-term unemployed people. The paper also highlights some of the methodological contributions of the demonstration, such as the use of cross-office analysis to learn from positive impacts in order to refine policy and, in time, raise overall effectiveness. Launched in 2003 in selected Jobcentre Plus offices, which administer Government cash benefits and employment services, the programme was envisioned as a 'next step' in British welfare-to-work policies. Participants in ERA had access to a distinctive set of 'post-employment' job coaching and financial incentives, which were added to the job placement services that unemployed people could normally receive through Jobcentre Plus. Once employed, ERA participants could receive at least 2 years of advice and assistance from an employment adviser to help them continue working and advance in work. Those who consistently worked full time could receive substantial cash rewards, called 'retention bonuses'. Participants could also receive help with tuition costs and cash rewards for completing training courses while employed. The programme has been carefully evaluated though a large-scale randomised control trial. 
ERA targeted three important groups with different views on and preparation for work and advancement:

- 'The NDLP group': Unemployed lone parents receiving Income Support ${ }^{1}$ and volunteering for the New Deal for Lone Parents (NDLP) welfare-to-work programme;

- 'The WTC group': Lone parents working part time and receiving Working Tax Credit (WTC), which supplements the wages of low-paid workers;

- 'The ND25+ group': Long-term unemployed people aged 25 or older receiving Jobseeker's Allowance ${ }^{2}$ and who were required to participate in the New Deal 25 Plus (ND25+) welfare-to-work programme.

These target groups faced somewhat different types of challenges that impeded their success in the labour market. A goal of the evaluation was to determine whether ERA could help each of them similarly, and whether it worked better for some than others. This paper thus compares the results for all three target groups and provides the final evidence of the programme's effectiveness over a 5-year follow-up period.

Over 16,000 people from six regions of Britain (East Midlands, London, North East England, North West England, Scotland, and Wales) applied to the programme. Random assignment was used in order to conclusively test whether or not ERA helped participants work more, earn more, advance further and achieve better outcomes in other specific areas. Half of the participants were randomly assigned to the programme, while the remainder served as a 'business-as-usual' control group-a counterfactual which did not receive any assistance from ERA and thus provided a benchmark indicating what would have happened in the absence of the ERA programme. ${ }^{3}$

\subsection{Findings in brief}

Prior to the launch of ERA, the New Deal programmes and Jobcentre Plus offered little further assistance to participants once they obtained jobs. Thus, ERA was a major departure from the 'business as usual' approach, and there was no guarantee that Jobcentre Plus could implement the model. The evaluation found that, after initial start-up problems, and despite variations in quality across offices and staff, ERA was largely implemented as designed, attesting that it was feasible to attach a post-employment component to the work of Jobcentre Plus or other employment agencies.

ERA produced short-term earnings gains for the two lone parent target groups: the NDLP and WTC groups, which were made up mostly of women. The early gains resulted from increases in the proportion of participants who worked full time (at least $30 \mathrm{~h}$ per week). This pattern aligns with the programme's requirement that participants work full time in order to qualify for the employment retention bonus. These effects generally faded in the later years, after the programme ended. However, an earnings gain appears to have lasted longer among NDLP participants who were better educated, though initially unemployed. Compared with other unemployed lone parents, this group may have had more unrealised potential to succeed in work, which ERA may have tapped into. From a costbenefit perspective, ERA did not produce encouraging results for the lone parent groups, with the exception of the NDLP better-educated subgroup. 
More impressive were the results for the long-term unemployed participants (mostly men) in the ND25+ target group. For them, ERA produced modest but sustained increases in employment and substantial and sustained increases in earnings. These positive effects emerged after the first year and were still evident at the end of the follow-up period. The earnings gains were accompanied by lasting reductions in benefits receipt over the 5-year follow-up period. ERA proved cost-effective for this group from the perspectives of the participants themselves, the government budget, and society as a whole. This is a noteworthy achievement for a group that is widely considered among the most difficult to help.

\section{Background}

ERA addressed the problem of low rates of employment retention and advancement among disadvantaged workers. Recurring unemployment and a lack of advancement are common among disadvantaged and low-paid workers. Many become entrenched in a 'low-pay, no-pay' cycle in which they shift repeatedly between low-wage work and unemployment. Often these individuals seek government benefits to supplement their incomes. Importantly, the 'low-pay, no-pay' cycle may persist even during periods of high aggregate employment levels; it is not simply a consequence of weak labour demand (Nunn et al., 2007).

Research has demonstrated that many individuals who struggle to retain employment and advance in work face a multitude of barriers to finding and keeping well-paid jobs, including low education levels, difficulties accessing transport, and poor health. Some studies suggest that moving frequently between work and benefits may have a 'scarring' effect, because individuals who spend more than a few weeks unemployed have been shown to experience chronic difficulty in re-establishing themselves in the labour market (Arulampalam, 2001). Recent research from the US suggests that those who have been out of the labour market six months or longer are much less likely to receive calls for interviews, even when they have relevant experience (Kroft et al., 2013). Some research also suggests that the experience of low-wage employment may have almost as large an effect as unemployment on future prospects (Stewart, 2007). In the wake of the great recession, concerns have also mounted about prospects for the long term unemployed (Elsby et al. 2010).

Low-wage workers tend to leave jobs for a variety of reasons. For example, some have short-term contracts, which they often accept reluctantly because they have difficulty finding more permanent employment. Some, of course, cannot meet employers' performance expectations. Others leave work by choice, because the jobs are not the kind of work they want to do, they are unhappy with the pay or work conditions, or they experience situational problems that undermine their performance. Lone parents often encounter particular difficulties with the cost and reliability of childcare and transport, balancing work and childcare responsibilities, and employers who are unwilling to accommodate their employees' family responsibilities.

Advancing within work is also increasingly difficult for low-wage workers. In fact, wage mobility in the UK has declined since the 1980s (Dickens 2000b; Stewart and Swaffield, 1999), and earnings volatility has declined (although not significantly) since the 1990s (Cappellari and Jenkins, 2014). Wage inequality, after growing strongly in the 
1980s, moderated in the early 1990s before growing again in the late 1990s (Blundell and Etheridge, 2010). Instead of moving into better jobs over time, many low-wage workers remain stuck in low-level positions that require few higher skills, are often part time or temporary, and offer few opportunities for training (Dickens, 2000a unpublished). Such conditions make it difficult to climb a career ladder. Some research also suggests that employees who earn the lowest wages and whose working conditions are poor are generally less able to negotiate better working conditions for themselves (Dex and Smith, 2001) and are actually more likely to return to benefits than to improve their earnings (Dickens 2000b). Lone parents who work face the added challenge of balancing family and work responsibilities, which may make it more difficult to pursue advancement opportunities, including working longer hours.

Earnings supplements as a policy response. In recent years, there have been a number of experimental programmes using randomised control trials (RCTs) to examine the effects of temporary earnings supplements provided to individuals to support them in the early months of new employment (Blank et al. 1999; Martinson \& Hamilton, 2011; Michalopoulos et al., 2005). It is well known that high rates of job loss are related to low wages and other poor job characteristics (Stewart, 2007; Hershey \& Pavetti, 1997). From this perspective, the earnings supplement increases the effective wage during the first year of employment, which helps "make work pay" during a period when most entrants are earning entry level wages.

Several earlier studies have shown that provision of financial incentives can promote employment among low-wage workers. Rigorous evaluations using random assignment experiments of several financial incentive programmes, including the Minnesota Family Investment Program (MFIP), the New Hope Project, and the Canadian Self-Sufficiency Project (SSP) are remarkably consistent in demonstrating positive effects on economic outcomes (Michalopoulos et al. 2005). This research shows that individuals offered financial incentives are more likely to work, earn more, and have more income than those in a control group not offered the financial incentives. While all of these programmes produced positive effects on employment during the operational period, the effects subsequently faded soon before or just after the financial incentives ended mostly due to control group members "catching up" to the progress of programme group members.

A subsequent generation of programmes targeting out-of-work welfare recipients has combined financial incentives with a variety of employment related services aimed at helping the recipients find and retain jobs. The services provided by these programmes ranged from simple job search assistance to more extensive services prior to and after jobs were found. SSP Plus, an experimental programme providing financial incentives and limited employment services to single-parent families on welfare in Canada, found sustained effects that exceeded those from a programme that provided financial incentives alone (Robins et al., 2008). More recently, one programme in the Employment Retention and Advancement demonstration in the United States (Texas ERA) provided both financial incentives and a rich assortment of pre- and post-employment services to encourage stable employment. A multi-site randomised control trial of Texas ERA showed some statistically significant increases in employment and earnings, particularly for the Corpus Christi site. These effects persisted through the end of the 4 year follow-up period (Hendra et al., 2010). The Employment 
Retention and Advancement programme in the United Kingdom (UK ERA) represents the first European RCT of this policy strategy.

\subsection{Policy context}

ERA was envisioned as a next step in Britain's 'welfare-to-work' policy, which has been evolving since the early 1970s, when the government began supplementing the wages of working families to help them overcome the cycle of unemployment and in-work poverty.

In its third year in office in 1999, the Labour Government faced a quarter to a third of children living in relative poverty-a rate that, if measured by the contemporary index of the proportion of families with incomes below 60 per cent of the national median, had doubled between 1979 and 1995. More than half of lone parents remained out of work. In response, the government made two important pledges:

- to halve the child poverty rate by 2010 and to eliminate child poverty by 2020 , and

- to raise the proportion of lone parents in paid work for at least some hours each week to 70 per cent by 2010 .

The policies that ensued-particularly those directed at lone parents-were largely aimed at meeting these goals. For example, tax credits were designed to 'make work pay' by providing enough incentive to work while meeting the increasing challenge of keeping low-paid workers' standards of living in sync with those of the working majority who have higher earnings. In 1999, the Working Families Tax Credit was introduced, offering more generous wage supplements to low-income workers as well as help covering most of the formal cost of childcare. This reform was underpinned by the National Minimum Wage, which took effect in the same year, and which many believed was essential, in part, in order to prevent employers from reducing wages in the face of higher government-funded wage supplements. In 2003, the Working Families Tax Credit was replaced by the Working Tax Credit, which was the first major tax credit also available to low-paid workers without children, and the Child Tax Credit, which simplified support so that families with children could have a clearer idea of how much they could expect to receive in and out of work.

The policy environment has changed substantially since the time of the ERA evaluation. In particular, a new active labour market programme-the 'Work Programme'-replaced the New Deal provision in June 2011, and the system of welfare payment in place at the time of the experiment is being replaced with a single "Universal Credit". However, the ERA evidence remains highly relevant in particular due to the focus on in-work support to help part time workers as well as ERA's emphasis (and effectiveness) on helping the long term unemployed back into the labour market. The current government in the United Kingdom has identified in-work progression as an important priority in its welfare reform agenda and is actively exploring innovative ways to promote in-work progression under the universal credit.

\subsection{The ERA programme}

Table 1 summarises the staff and services available through ERA compared with the services available to participants who were not in ERA. The core of the ERA 
Table 1 Staff, incentives, and services available to ERA (programme group) and non-ERA (control group) customers

\begin{tabular}{|c|c|c|c|c|}
\hline \multirow[t]{3}{*}{ Feature } & \multicolumn{2}{|c|}{ New Deal Target Groups } & \multicolumn{2}{|l|}{ WTC } \\
\hline & ERA & $\overline{\text { Non-ERA }}$ & ERA & Non-ERA \\
\hline & (Programme) & (Control) & (Programme) & (Control) \\
\hline \multicolumn{5}{|l|}{ Job coaching staff } \\
\hline \multicolumn{5}{|l|}{ - PA: Personal Adviser } \\
\hline - ASA: Advancement Support Adviser & ASA & PA & ASA & \\
\hline Eligible for New Deal pre-employment services & $\checkmark$ & $\checkmark$ & & \\
\hline \multicolumn{5}{|l|}{ - Job placement assistance } \\
\hline \multicolumn{5}{|l|}{ - Advice on training and increasing skills } \\
\hline Eligible for in-work support & $\checkmark$ & & $\checkmark$ & \\
\hline \multicolumn{5}{|l|}{$\begin{array}{l}\text { - Coaching on advancement in current position } \\
\text { and/or finding a better job }\end{array}$} \\
\hline \multicolumn{5}{|l|}{ - Rapid re-employment services when necessary } \\
\hline Eligible for in-work bonuses & $\checkmark$ & & $\checkmark$ & \\
\hline \multicolumn{5}{|l|}{$\begin{array}{l}\text { - Retention Bonus: Up to six payments of } £ 400 \\
\text { for each period when customers work } 30 \text { or } \\
\text { more hours per week for } 13 \text { out of } 17 \text { weeks }\end{array}$} \\
\hline \multicolumn{5}{|l|}{$\begin{array}{l}\text { - Training Bonus: Tuition payment of up to } £ 1,000 \\
\text { if training undertaken while working; if training is } \\
\text { successfully completed, } £ 8 \text { for every hour of } \\
\text { training, up to } £ 1,000\end{array}$} \\
\hline Eligible to receive Adviser Discretion Fund (ADF) money & $\checkmark$ & $\checkmark$ & & \\
\hline \multicolumn{5}{|l|}{$\begin{array}{l}\text { - Pre-employment funds available to help customers } \\
\text { obtain work }\end{array}$} \\
\hline Eligible to receive Emergency Discretion Fund (EDF) money & $\checkmark$ & & $\checkmark$ & \\
\hline - In-work funds available to help customers stay employed & & & & \\
\hline
\end{tabular}

intervention included extensive advisory coaching and support, financial incentives to make work pay, and financial incentives to encourage training participation. These elements are described in more detail below.

\subsubsection{Advisory support}

Individuals assigned to the ERA programme worked with an Advancement Support Adviser who provided job coaching for a maximum of 33 months over both preemployment and in-work periods. ERA participants in the WTC group who were already working would begin receiving in-work support immediately but would still receive support for up to 33 months.

ERA was designed so that, in the pre-employment stage, advisers coached their ERA participants to consider the advancement opportunities of a job before taking it and to try to identify work that would be a good fit with their skills and interests. Once in work, coaching continued in order to help participants address any continuing or new barriers to their employment and to help them advance in their work. To guide their work with participants, advisers developed a personalised Advancement Action Plan with each of them, which set out job search, retention, and advancement steps.

ERA advisers also had access to an Emergency Discretion Fund, which was a pool of up to $£ 300$ per participant to avert minor financial emergencies that threatened to 
prevent a participant from continuing in work, such as the need for special clothing, new tools, car repairs, or help with short-term childcare problems.

\subsubsection{Financial incentives}

In addition, the ERA programme included financial incentives designed to promote work retention and advancement.

2.2.2.1 Employment retention bonus To motivate ERA participants to enter full-time work, and to do so earlier than they might normally have considered, ERA offered up to six payments of $£ 400$ when participants worked 30 or more hours per week ${ }^{4}$ for 13 out of 17 weeks (or about 75 per cent of the time). ${ }^{5}$ This amounted to $£ 2,400$ for a participant who received all six payments. ${ }^{6}$

Participants were required to provide evidence of their employment and hours by showing wage slips and to come into the office to claim their retention bonus. This contact provided another opportunity for face-to-face interaction with their adviser.

2.2.2.2 Training bonus ERA participants were also eligible for financial incentives to combine work with training. This was intended to encourage them to invest time and effort in developing skills that might promote their long-term career progression. While in work for at least $16 \mathrm{~h}$ per week, participants qualified for tuition payments of up to $£ 1,000$ for approved courses that reflected the agreed goals in their own Advancement Action Plans and corresponded with local labour market needs. These payments were made directly to the training providers.

Participants who successfully completed an approved course received an additional bonus of $£ 8$ for every hour of training completed, up to a maximum of $£ 1,000$ (or $125 \mathrm{~h}$ ).

\section{The UK ERA evaluation}

\subsection{Random assignment}

Entering into the random assignment study was voluntary for qualifying members of the three target groups. When they came into Jobcentre Plus offices, their basic demographic information was recorded and they were informed of the possible advantages of participating in the ERA programme. They were then invited to enter the demonstration 'lottery', told that they had a 50 per cent chance of being selected for the programme, and asked to sign an informed consent form in which they agreed to allow researchers access to certain types of data about them, whether they were assigned to the ERA programme group or to the control group. ${ }^{7}$ After completing an informed consent process $^{8}$, half of the participants were assigned randomly to the ERA programme group, and the rest to a control group. Those in the control group could continue to receive whatever services they were normally entitled to receive from Jobcentre Plus or could obtain elsewhere in the community. Thus, control group members in the two New Deal customer groups went on to receive regular New Deal pre-employment services but were expected to have little regular or intensive involvement with Jobcentre Plus staff after entering work. Control group members in the WTC target group would not normally enter the New Deal programme because they were not receiving Income Support or Jobseeker's Allowance. Therefore, they were not offered pre- or post-employment services or 
incentives through Jobcentre Plus, though sometimes they sought advice from Jobcentre Plus staff on their own initiative and could seek other services or training on their own.

Random assignment was successfully carried out between October 2003 and April 2005. Across all six districts, 6,787 people entered the ERA research sample from NDLP, 2,815 people entered the sample as WTC recipients, and 6,782 people entered the sample from ND25+. As a result of random assignment, programme and control group members within each target group shared similar characteristics, on average, and baseline balance tests detected few statistically significant differences. This helped ensure that the control group would provide unbiased estimates of how programme group participants would have progressed over time had they never encountered ERA. Despite the similarities within the programme and control members of each the three targeted groups, there were relatively different social compositions between each of these groups, as shown in Table 2 and discussed below. ${ }^{9}$

NDLP group. NDLP sample members were mostly young to middle-aged women; 95 per cent were female. Over 80 per cent were under 40 , and 15 per cent were racial/ethnic minorities. This generally aligned with the demographics of NDLP entrants nationwide.

NDLP sample members faced significant barriers to work. About a quarter had no educational qualifications, just under half had reached General Certificate of Secondary Education (GCSE) level, and fewer had A-level qualifications. ${ }^{10}$ Two-thirds lived in social housing (housing owned by the local government or a private housing association), and only about a quarter lived in privately owned or privately rented accommodation. Over two-thirds did not have a driving licence or access to a vehicle, and almost two-thirds cited barriers to work (which could include housing, transport, childcare, health, basic skills, or other problems). Nearly half did not work at all in the 3 years before random assignment, and just over a quarter worked 13 months or more during this period. The children of the NDLP sample were quite young; the youngest child of 58 per cent of the sample was under the age of seven, and only 16 per cent of sample members had a youngest child over the age of 12 at the time of randomisation.

WTC group. Almost all of the WTC sample members were women. The WTC sample was older than the NDLP sample, as nearly half were in their 30s, and another 36 per cent were age 40 or older. As would be expected, the youngest child of members of the WTC sample was older than that of the NDLP sample, with 62 per cent over the age of seven and 30 per cent over the age of 12 at the time of randomisation.

The lone parents receiving WTC differed from the NDLP group in ways that underscore the differences between groups of people who had worked more steadily and those who had been out of work. Nearly 90 per cent of the WTC group reported working 13 months or more in the 3 years before random assignment. In the WTC group, very few reported no work experience in the 3 years before random assignment, as they had to be working at the time of random assignment to enter ERA.

This group also reported better qualifications than the NDLP group, with only 12 per cent having no qualifications at all and a greater percentage having qualifications beyond a GCSE. Over half lived in privately owned or privately rented housing, a proportion much greater than among the NDLP sample members. They had fewer transport barriers as well; only one-third reported no driving licence or access to a vehicle, compared with two-thirds of the NDLP sample members. However, the WTC sample members were almost as likely to report facing barriers to work; in their case, they seem to have overcome these obstacles. 
Table 2 Demographic profile of all customers randomly assigned between October 2003 and April 2005

\begin{tabular}{|c|c|c|c|}
\hline Characteristic & New Deal for Lone Parents & Working Tax Credit & New Deal 25 Plus \\
\hline \multicolumn{4}{|l|}{ Gender (\%) } \\
\hline Male & 5.0 & 2.6 & 81.1 \\
\hline Female & 95.0 & 97.4 & 18.9 \\
\hline \multicolumn{4}{|l|}{ Age (\%) } \\
\hline Under 30 & 41.3 & 17.0 & 16.3 \\
\hline $30-39$ & 39.7 & 47.1 & 36.8 \\
\hline 40 or older & 19.0 & 35.9 & 46.9 \\
\hline \multicolumn{4}{|l|}{ Age of youngest child (\%) ${ }^{\mathrm{a}}$} \\
\hline No children & 1.0 & 1.4 & 84.0 \\
\hline Under 7 & 57.8 & 36.8 & 8.9 \\
\hline $7-11$ & 25.4 & 31.8 & 3.0 \\
\hline $12-16$ & 15.3 & 25.9 & 2.3 \\
\hline 17 or older & 0.5 & 4.1 & 1.8 \\
\hline \multicolumn{4}{|l|}{ Race/ethnicity (\%) } \\
\hline Ethnic minority & 14.8 & 7.8 & 21.5 \\
\hline White & 85.2 & 92.2 & 78.5 \\
\hline \multicolumn{4}{|l|}{ Education (highest qualification obtained) ${ }^{\mathrm{b}}(\%)$} \\
\hline None & 23.2 & 12.1 & 36.3 \\
\hline GCSE & 47.7 & 45.0 & 26.9 \\
\hline A-level & 21.6 & 30.7 & 23.6 \\
\hline Other & 7.6 & 12.2 & 13.2 \\
\hline \multicolumn{4}{|l|}{ Housing status ${ }^{\mathrm{c}}(\%)$} \\
\hline Family & 7.6 & 6.0 & 23.1 \\
\hline Social & 66.5 & 37.6 & 45.9 \\
\hline Private & 26.0 & 56.3 & 31.0 \\
\hline \multicolumn{4}{|c|}{ Number of months worked in 3 years prior to random assignment (\%) } \\
\hline None & 49.6 & 1.2 & 45.5 \\
\hline $1-12$ & 23.1 & 11.6 & 33.8 \\
\hline $13+$ & 27.3 & 87.2 & 20.7 \\
\hline \multicolumn{4}{|l|}{ Cohort (\%) } \\
\hline Early (October 2003 - May 2004) & 52.1 & 19.1 & 47.8 \\
\hline Late (June 2004 - April 2005) & 47.9 & 80.9 & 52.2 \\
\hline No driving licence or lack of access to vehicle (\%) & 67.5 & 33.1 & 77.2 \\
\hline Has barriers to work ${ }^{d}(\%)$ & 65.3 & 68.0 & 62.9 \\
\hline Severely disadvantaged ${ }^{\mathrm{e}}(\%)$ & 23.1 & NA & 20.1 \\
\hline Moderately disadvantaged ${ }^{f}(\%)$ & NA & 37.3 & NA \\
\hline Sample size & 6,787 & 2,815 & 6,782 \\
\hline
\end{tabular}

SOURCE: MDRC calculations from baseline information forms completed by DWP staff

NOTES: Rounding may cause slight discrepancies in calculating sums and differences. Sample includes all lone parent customers and all New Deal 25 Plus customers randomly assigned between October 2003 and April 2005

${ }^{a}$ Child's age is asked only for children who are living with the customer

${ }^{\mathrm{b}}$ Customers who have General Certificate of Secondary Education (GCSE) qualifications refers to those who have passed a series of examinations in a variety of subjects, usually taken at age 15 or 16 . Those with A-level qualifications have passed a series of more advanced examinations usually taken around age 18 or older. Those with no qualifications have completed neither series of examinations

${ }^{c}$ Family housing refers to situations where the customer is living with his/her parents or other friends or relatives. Social housing refers to housing in which the Local Authority (local government) or a private housing association is the landlord. Private housing refers to owner-occupied housing or housing that the customer rents privately

${ }^{\mathrm{d}}$ Barriers to work include housing, transport, childcare, health, basic skills, or other problems

eSeverely disadvantaged refers to those NDLP customers with GCSE qualifications or lower, no work in the 3 years prior to random assignment, and at least one barrier to employment

${ }^{f}$ Moderately disadvantaged refers to those WTC customers with GCSE qualifications or lower and at least one barrier to employment 
ND25+ group. ND25+ sample members differed in several ways from the lone parent target groups. ND25+ sample members were largely older men-81 per cent were male, nearly half were age 40 or older, and 84 per cent were age 30 or older. Sixteen per cent had dependent children at home, while more had children living elsewhere. Twenty-two per cent were ethnic minorities-a higher proportion of ethnic minorities than either of the two lone parent groups in ERA. More than a third had no educational qualifications at all. The largest proportion (46 per cent) lived in social housing; 31 per cent lived in private housing. Less than a quarter of the ND25+ sample members had a driving licence and access to a vehicle. Nearly two-thirds cited barriers to work, 46 per cent had no work experience in the three years before random assignment, and only 21 per cent said that they worked more than a year during that time.

\subsection{Data and methods}

The impact analysis relies heavily on administrative data. Employment and earnings administrative records data were provided to DWP by Her Majesty's Revenue and Customs and maintained in DWP's Work and Pensions Longitudinal Study (WPLS) database. Benefits receipt data available from DWP are the primary source of benefits information. In addition, data are available from three waves ${ }^{11}$ of a longitudinal customer survey administered at 12, 24, and 60 months following each individual's date of random assignment (when they entered the study). ${ }^{12}$ The survey data provide a basis for assessing how much ERA participants used ERA's employmentrelated services and incentives and how much participants' receipt of training and other services differed from that of controls (who were free to seek alternative services on their own from Jobcentre Plus or other agencies).

The study also uses qualitative research (i.e., in-depth interviews with ERA staff and participants), along with financial data on bonus receipt and other programme records, to provide further insights into the experiences of operating ERA within Jobcentre Plus, participants' responses to the programme, and participants' experiences in work.

Results presented in this paper are based on "intent-to-treat" impact estimates. That is, the impacts are calculated by comparing all individuals in the programme group with all individuals assigned to the control group, regardless of whether or how long they were engaged in $U K E R A$ services. The impacts were regressionadjusted using background characteristics of the sample such as prior earnings, education, household characteristics, and relative month of random assignment.

The following equation was used to estimate the impacts of UK ERA:

$$
Y_{i}=\alpha+\beta P_{i}+\delta X_{i}+\varepsilon_{i}
$$

where: $Y_{j}=$ the outcome measure for sample member $i, P_{i}=$ one for programme group members and zero for control group members, $X_{i}=a$ set of background characteristics for sample member i, $\varepsilon_{i}=$ a random error term for sample member $i, \beta=$ the estimate of the impact of the programme on the average value of the outcome, $\alpha=$ the intercept of the regression, and $\delta=$ the set of regression coefficients for the background characteristics. ${ }^{13}$ 


\section{Results}

4.0.0.1 Implementation results Researchers conducted multiple rounds of in-depth qualitative interviews with both staff and programme group members from 2004 through spring 2009. These data form the bulk of the data used for the implementation and process analyses of ERA. Those analyses also relied on weekly diaries that Technical Advisers kept from the beginning of random assignment through June 2005, as well as on data collected on site visits and observations they made at various points throughout the course of ERA.

The implementation analysis found that ERA was largely implemented as designed, although the amount and quality of retention and advancement support offered to participants varied over time and across districts. Employed ERA participants in all three target groups experienced substantially higher levels of advancement-related support from Jobcentre Plus compared with employed control group members.

At the time ERA was launched, line staff and managers alike were inexperienced in delivering an advancement-focused intervention, and the institutional incentives under which they operated offered little encouragement to focus on advancementrelated outcomes. Not surprisingly, the agency encountered many difficulties along the way, and the quality with which ERA was implemented varied across local Jobcentre Plus districts, offices, and staff. However, over time and with much effort, implementation grew stronger, and Jobcentre Plus was able to deliver the core elements of the model. ${ }^{14}$ Overall, substantially higher proportions of working ERA participants were engaged with Jobcentre Plus and received advancementrelated assistance while employed compared with their control group counterparts.

Data from the 2-year customer survey show that, among respondents who had worked during the follow-up period, those in the programme group, on average, had substantially more contact with a Jobcentre Plus adviser while working and received more help and guidance on advancement compared with their counterparts in the control group (see Fig. 1). ${ }^{15}$ For example, within the NDLP target group, 81 per cent of employed ERA participants had reported some in-work contact with Jobcentre Plus staff, compared with 42 per cent of those in the control group. Large differentials were also evident for the WTC and ND25+ samples.

The quality of the contact also differed considerably, with higher proportions of ERA participants than control group members reporting face-to-face contact with Jobcentre Plus staff and greater receipt of employment retention and advancement advice. For example, among survey respondents who had worked, the proportion who reported having received help or advice on retention and advancement while in work' was between three and ten times greater for ERA participants than controls. Together, these findings confirm that engagement with Jobcentre Plus was much different for employed ERA participants than for employed individuals who were not part of ERA.

4.0.0.2 Advancement-focused support ERA advisers tried to promote the programme's advancement goals in a variety of ways. According to participants' responses to the 2-year survey, advancement-related coaching and advice focused most often on the following activities: help finding education or training, determining career goals, 


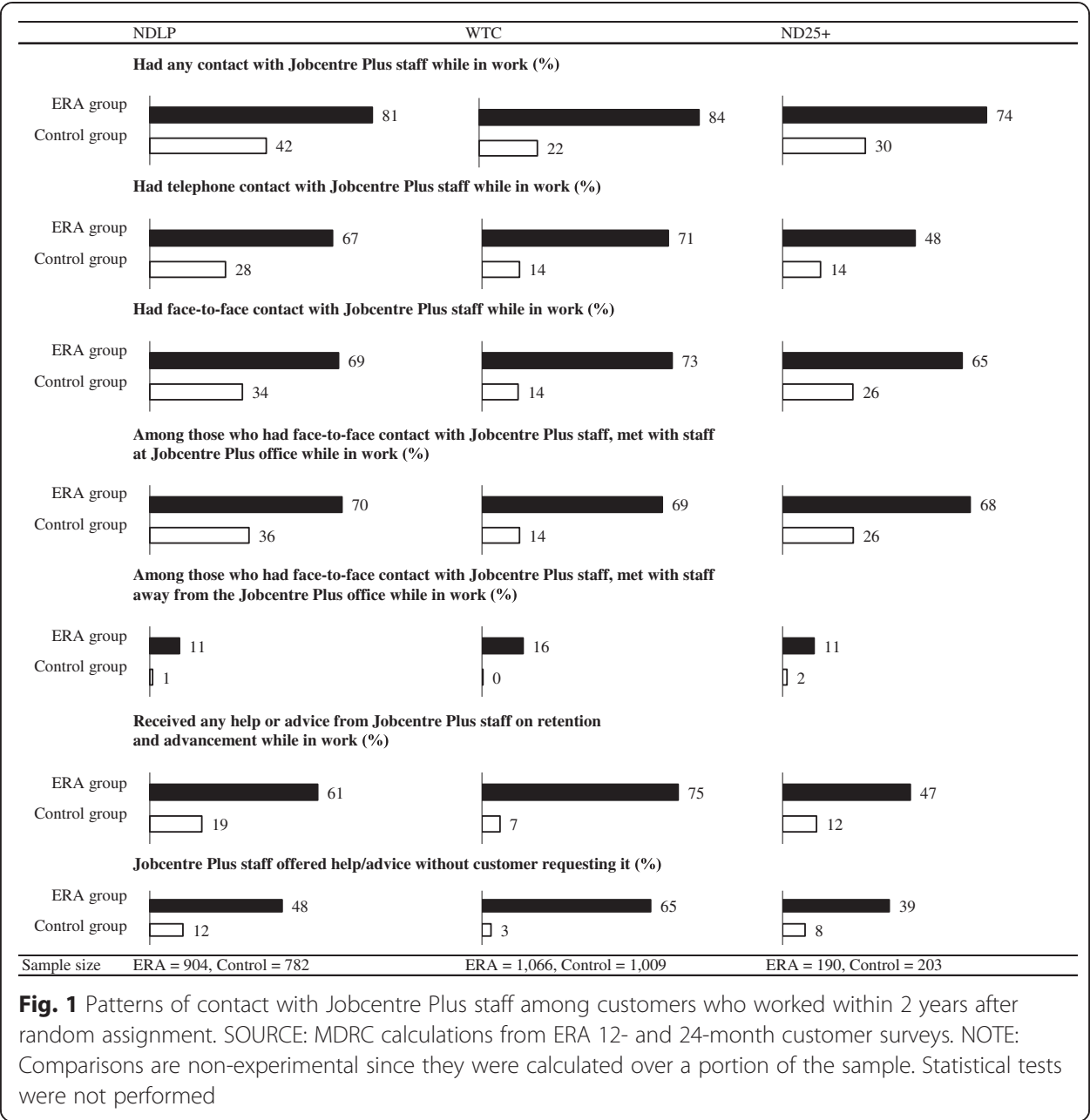

increasing work hours, and getting a better job (Table 3). Less common were: support in getting a promotion, negotiating better job terms, and negotiating a pay rise.

ERA advisers recognised that the three target groups faced different types of employment challenges and often had different views towards advancement. In general, staff believed that the two lone parent groups (NDLP and WTC) were more responsive to ERA than the long-term unemployed group (ND25+). However, they also acknowledged some important differences within each target group.

Lone parents in the WTC programme group were already in work and had stronger work histories on the whole. Thus, they were less likely to have job retention problems and were more receptive to exploring advancement opportunities. Indeed, much of the in-work support advisers provided to WTC participants focused on meeting the progression goals set out in their individual Advancement Action Plans.

ND25+ participants had the lowest rates of in-work support among the three ERA programme groups. About a quarter of those who were working said on the 2-year survey that they had no contact with Jobcentre Plus staff while they were employed. In the qualitative interviews, ERA advisers reported great difficulty engaging these participants. They suggested a number of reasons, including the fact 
Table 3 Receipt of in-work help or advice from Jobcentre Plus staff within 2 years after random assignment among customers who worked

\begin{tabular}{|c|c|c|c|c|c|c|}
\hline \multirow[t]{2}{*}{ Outcome } & \multicolumn{2}{|l|}{ NDLP } & \multicolumn{2}{|l|}{ WTC } & \multicolumn{2}{|l|}{ ND25+ } \\
\hline & $\begin{array}{l}\text { ERA } \\
\text { group }\end{array}$ & $\begin{array}{l}\text { Control } \\
\text { group }\end{array}$ & $\begin{array}{l}\text { ERA } \\
\text { group }\end{array}$ & $\begin{array}{l}\text { Control } \\
\text { group }\end{array}$ & $\begin{array}{l}\text { ERA } \\
\text { group }\end{array}$ & $\begin{array}{l}\text { Control } \\
\text { group }\end{array}$ \\
\hline $\begin{array}{l}\text { While in work, received help or advice dealing } \\
\text { with personal or family problems that made job } \\
\text { retention hard (\%) }\end{array}$ & 21.4 & 6.7 & 12.9 & 1.6 & 6.1 & 4.9 \\
\hline $\begin{array}{l}\text { While in work, received help or advice dealing with } \\
\text { problems at work (\%) }\end{array}$ & 13.2 & 3.8 & 7.9 & 0.8 & 10.7 & 4.4 \\
\hline \multicolumn{7}{|l|}{ While in work, received any help or advice on (\%) } \\
\hline Getting job with better pay or conditions & 31.9 & 9.4 & 47.7 & 3.4 & 21.0 & 6.1 \\
\hline Increasing hours of work & 30.3 & 9.0 & 52.8 & 2.5 & 15.3 & 5.0 \\
\hline Negotiating a pay rise & 5.0 & 1.2 & 7.4 & 0.4 & 6.6 & 0.8 \\
\hline $\begin{array}{l}\text { Negotiating better job terms, e.g., more } \\
\text { convenient hours }\end{array}$ & 11.7 & 2.9 & 11.0 & 1.3 & 6.3 & 2.5 \\
\hline Getting a promotion in present work & 11.9 & 1.5 & 15.0 & 0.9 & 7.5 & -0.2 \\
\hline Getting a more permanent job or contract & 14.7 & 4.0 & 15.9 & 1.4 & 11.3 & 3.8 \\
\hline Working out long-term career goals & 32.5 & 6.7 & 50.0 & 2.3 & 23.6 & 6.1 \\
\hline Finding an training or education course & 44.5 & 9.6 & 65.1 & 3.1 & 34.5 & 10.3 \\
\hline Other type of help & 11.6 & 3.4 & 19.3 & 1.3 & 7.6 & 2.8 \\
\hline Any in-work help/advice & 61.3 & 18.7 & 75.2 & 6.9 & 45.8 & 13.0 \\
\hline Sample size & 904 & 782 & 1,066 & 1,009 & 190 & 203 \\
\hline
\end{tabular}

SOURCE: MDRC calculations from ERA 12- and 24-month customer surveys

NOTES: Rounding may cause slight discrepancies in calculating sums and differences

Comparisons are non-experimental since they were calculated over a portion of the sample. Statistical tests were not performed

that some ND25+ participants avoided contact with their advisers due to negative feelings about Jobcentre Plus, a greater ethos of self-reliance, and less awareness of available in-work support. The advisers believed that, on the whole, participants with a history of long-term unemployment were more interested in securing a stable, secure job as opposed to advancing in work. However, there were reports of some participants in this group becoming more receptive to post-employment support after settling into their jobs.

4.0.0.3 Receipt of the retention bonus The employment retention bonus was a central feature of the ERA model. According to financial payment records (Table 4), 45 per cent of WTC participants received an ERA retention bonus, which was higher than the rates for the NDLP and ND25+ groups (33 per cent and 35 per cent, respectively). WTC participants also received more payments. This pattern is consistent with the WTC group's greater overall attachment to the labour force. It is possible that some people who were eligible for the bonus did not claim it. ERA advisers who were interviewed noted that some participants felt there was a 'catch' associated with the receipt of the bonus and were therefore suspicious of the extra money. Some lone parents were unsure what impact the bonus would have on their WTC. Some ND25+ participants may have foregone the bonus because they were reluctant to engage with Jobcentre Plus once they had found work. In addition, evidence from qualitative interviews revealed that some participants were simply not aware that they were eligible. 
Table 4 Receipt of ERA employment retention bonuses

\begin{tabular}{llll}
\hline Outcome & NDLP & WTC & ND25+ \\
\hline Ever received bonus (\%) & 32.9 & 44.6 & 34.8 \\
Average number of bonuses received among customers with any bonuses & 3.8 & 4.0 & 3.7 \\
Number of bonuses received among customers with any bonuses (\%) & & & \\
One & 15.3 & 11.3 & 18.2 \\
Two & 13.3 & 12.4 & 12.3 \\
Three & 14.4 & 11.1 & 11.1 \\
Four & 14.6 & 13.3 & 15.7 \\
Five & 20.0 & 30.1 & 22.7 \\
Six & 22.3 & 21.9 & 20.1 \\
Sample size & 3,365 & 1,415 & 3,424 \\
\hline
\end{tabular}

SOURCE: MDRC calculations primarily from DWP financial incentives data

NOTE: The sample for this table consists of all those randomly assigned between October 2003 and April 2005

4.0.0.4 Receipt of training bonuses According to financial payment records, WTC programme group participants took advantage of training opportunities more than any other group during ERA. Their rate of receipt of training fees and the completion bonus was at least double that of the other target groups. About 34 per cent of all WTC participants received assistance with training fees, compared with 16 per cent of NDLP participants and 11 per cent of ND25+ participants (see Table 5). Average

Table 5 ERA participants' receipt of ERA training fee assistance and training completion bonuses

\begin{tabular}{|c|c|c|c|}
\hline Outcome & NDLP & WTC & ND25+ \\
\hline \multicolumn{4}{|l|}{ Training/tuition fee assistance } \\
\hline Received tutition fee assistance (\%) & 15.5 & 33.8 & 10.8 \\
\hline Average number of payments received among participants with any payments & 2.0 & 2.3 & 1.8 \\
\hline \multicolumn{4}{|l|}{ Number of payments received among participants with any payments (\%) } \\
\hline One & 54.7 & 47.1 & 58.0 \\
\hline Two & 21.6 & 21.3 & 23.6 \\
\hline Three & 10.9 & 13.8 & 10.6 \\
\hline Four or more & 12.8 & 17.8 & 7.9 \\
\hline Average amount of each payment among participants with any payments $(£)$ & 383 & 291 & 431 \\
\hline Average total amount of payments among participants with any payments ( $£$ ) & 579 & 510 & 616 \\
\hline \multicolumn{4}{|l|}{ Training completion bonus } \\
\hline Received bonus (\%) & 14.1 & 34.1 & 7.4 \\
\hline Average number of bonuses received among participants with any bonuses & 2.0 & 2.2 & 1.6 \\
\hline \multicolumn{4}{|l|}{ Number of bonuses received among participants with any bonuses (\%) } \\
\hline One & 55.3 & 48.1 & 65.5 \\
\hline Two & 22.7 & 25.3 & 18.4 \\
\hline Three & 11.6 & 12.9 & 10.2 \\
\hline Four or more & 10.5 & 13.7 & 5.9 \\
\hline Average amount of each bonus among participants with any bonuses $(£)$ & 394 & 402 & 345 \\
\hline Average total amount of bonuses among participants with any bonuses $(£)$ & 586 & 633 & 492 \\
\hline Sample size & 3,365 & 1,415 & 3,424 \\
\hline
\end{tabular}

SOURCE: MDRC calculations primarily from DWP financial incentives data

NOTE: The sample for this table consists of all those randomly assigned to the ERA programme group between October 2003 and April 2005 
payments among those who received tuition payments ranged from $£ 616$ for workers in the ND25+ group to $£ 579$ and $£ 510$, respectively, for working lone parents in the NDLP and WTC groups. WTC participants were more likely than the NDLP and $\mathrm{ND} 25+$ groups to receive training completion bonuses and were more likely to receive more than one such bonus.

As noted previously, some ERA advisers more actively promoted the training incentives towards the end of the programme, and this strategy is reflected in the financial payment records. Of participants who received training-related payments, about a third in the NDLP group, a fifth in the WTC group, and two-fifths in the ND25+ group received training fee payments for the first time within their last nine months of eligibility. Similarly, about two-fifths of NDLP bonus recipients, about a quarter of the WTC bonus recipients, and approximately a third of ND25+ bonus recipients received the training completion bonus for the first time in the last nine months.

\subsection{Core economic impact results}

\subsubsection{ERA's economic impacts for lone parents in the NDLP group}

For NDLP participants, balancing continuous employment with family responsibilities was typically the most immediate priority, with advancement a more distant goal. This created an important challenge for ERA. Because these lone parents were new to the labour market, they tended to want time to adjust to the new routines of working and balancing job and family responsibilities before focusing on advancement. And while some were interested in full-time work, others were not because of their family circumstances. Nonetheless, ERA increased this group's likelihood of working full time, at least early on.

ERA increased NDLP participants' employment and earnings in the short term, primarily by increasing their likelihood of working full time. However, these effects faded after participants' enrollment in the programme ended. Table 6 shows the impacts of ERA on key economic outcomes for each target group. For NDLP lone parents, who were not employed when they began ERA, ERA increased employment and earnings within the first 2 years, but the effects faded thereafter. ERA also increased earnings in the first full tax year after participants' enrollment (tax year 2005-2006) by an estimated $£ 308$, a statistically significant gain of about nine per cent over the control group average. (The earnings outcomes for each group are averaged over all sample members in the group, whether or not they worked; the estimates do not refer to earnings per worker.) The impact was smaller in later tax years, and the cumulative effect on earnings over the four tax years for which data were analysed (2005-2006 through $2008-2009)^{16}$ is not statistically significant.

Earnings effects can arise due to an increase in the likelihood and duration of employment, hours worked, or wage rates. The fact that the earnings effect in 2005-2006, in percentage terms, was about double the employment effect in that same year suggests that the increase in earnings was driven in part by ERA group members working more hours or receiving higher wages. ${ }^{17}$ According to data from the 2-year customer survey, ERA increased the proportion of NDLP participants who worked full time, probably in response to the programme's retention bonus, which rewarded only full-time work. Data from the 60-month survey, compared with earlier surveys, indicate that this effect did not persist, as the control group increasingly worked full time and closed the gap. 
Table 6 Effects of ERA on employment, earnings, and benefits within 5 years after random assignment, New Deal for Lone Parents, Working Tax Credit, and New Deal 25 Plus target groups

\begin{tabular}{|c|c|c|c|c|c|c|c|c|c|c|c|c|}
\hline \multirow[t]{2}{*}{ Outcome } & \multicolumn{4}{|l|}{ NDLP } & \multicolumn{4}{|l|}{ WTC } & \multicolumn{4}{|l|}{ ND25+ } \\
\hline & $\begin{array}{l}\text { ERA } \\
\text { group }\end{array}$ & $\begin{array}{l}\text { Control } \\
\text { group }\end{array}$ & $\begin{array}{l}\text { Difference } \\
\text { (impact) }\end{array}$ & $\begin{array}{l}\text { Percentage } \\
\text { change }\end{array}$ & $\begin{array}{l}\text { ERA } \\
\text { group }\end{array}$ & $\begin{array}{l}\text { Control } \\
\text { group }\end{array}$ & $\begin{array}{l}\text { Difference } \\
\text { (impact) }\end{array}$ & $\begin{array}{l}\text { Percentage } \\
\text { change }\end{array}$ & $\begin{array}{l}\text { ERA } \\
\text { group }\end{array}$ & $\begin{array}{l}\text { Control } \\
\text { group }\end{array}$ & $\begin{array}{l}\text { Difference } \\
\text { (impact) }\end{array}$ & $\begin{array}{l}\text { Percentage } \\
\text { change }\end{array}$ \\
\hline \multicolumn{13}{|l|}{ Ever employed (\%) } \\
\hline Year 1 & 57.1 & 56.5 & 0.6 & 1.0 & 77.0 & 76.6 & 0.4 & 0.6 & 37.3 & 35.4 & $1.9^{*}$ & 5.3 \\
\hline Year 2 & 57.8 & 55.6 & $2.2^{*}$ & 3.9 & 74.1 & 73.4 & 0.8 & 1.0 & 36.3 & 32.7 & $3.6^{* * *}$ & 11.0 \\
\hline Year 3 & 53.7 & 53.8 & -0.2 & -0.3 & 71.2 & 69.9 & 1.3 & 1.8 & 34.6 & 32.5 & $2.1^{*}$ & 6.6 \\
\hline Year 4 & 53.2 & 54.0 & -0.8 & -1.5 & 71.3 & 70.1 & 1.2 & 1.8 & 35.0 & 32.1 & $2.9^{* * *}$ & 9.1 \\
\hline Year 5 & 52.9 & 53.9 & -1.0 & -1.8 & 68.6 & 68.2 & 0.3 & 0.5 & 32.8 & 30.9 & $1.9^{*}$ & 6.0 \\
\hline Years 1-5 & 79.0 & 79.0 & -0.1 & -0.1 & 88.1 & 86.8 & 1.3 & 1.5 & 57.3 & 55.1 & $2.2^{*}$ & 4.0 \\
\hline \multicolumn{13}{|l|}{ Average earnings ( $(£)$} \\
\hline 2005-2006 tax year & 3,862 & 3,554 & $308^{* *}$ & 8.7 & 7,069 & 6,667 & $402^{* *}$ & 6.0 & 3,070 & 2,758 & $312^{* *}$ & 11.3 \\
\hline 2006-2007 tax year & 4,032 & 3,883 & 150 & 3.9 & 7,408 & 7,071 & 337 & 4.8 & 3,447 & 3,104 & $342^{* *}$ & 11.0 \\
\hline 2007-2008 tax year & 4,387 & 4,271 & 116 & 2.7 & 7,502 & 7,555 & -53 & -0.7 & 3,692 & 3,228 & $464^{* * *}$ & 14.4 \\
\hline 2008-2009 tax year & 4,999 & 5,033 & -35 & -0.7 & 8,636 & 8,401 & 234 & 2.8 & 3,954 & 3,591 & $363^{* *}$ & 10.1 \\
\hline 2005-2009 tax years, 4-year earnings & 17,280 & 16,742 & 538 & 3.2 & 30,615 & 29,695 & 921 & 3.1 & 14,162 & 12,681 & $1,481^{* *}$ & 11.7 \\
\hline \multicolumn{13}{|c|}{ Average total amount of benefits ${ }^{\mathrm{a}}$ received $(£)$} \\
\hline Year 1 & 2,915 & 3,055 & $-140^{* *}$ & -4.6 & 190 & 201 & -11 & -5.4 & 2,359 & 2,406 & -48 & -2.0 \\
\hline Year 2 & 2,000 & 2,130 & $-130^{* *}$ & -6.1 & 218 & 221 & -3 & -1.4 & 1,457 & 1,581 & $-124^{* * *}$ & -7.8 \\
\hline Year 3 & 1,663 & 1,773 & $-110^{*}$ & -6.2 & 254 & 241 & 13 & 5.3 & 1,244 & 1,358 & $-115^{* * *}$ & -8.4 \\
\hline Year 4 & 1,458 & 1,542 & -84 & -5.4 & 243 & 220 & 23 & 10.3 & 1,038 & 1,099 & $-61^{*}$ & -5.6 \\
\hline Year 5 & 1,314 & 1,349 & -35 & -2.6 & 285 & 266 & 19 & 7.1 & 970 & 1,048 & $-78^{* *}$ & -7.5 \\
\hline Years 1-5 & 9,349 & 9,848 & $-499^{* *}$ & -5.1 & 1,190 & 1,149 & 40 & 3.5 & 7,067 & 7,493 & $-426^{* * *}$ & -5.7 \\
\hline
\end{tabular}

SOURCE: MDRC calculations from Work and Pensions Longitudinal Study employment and benefits receipt records

NOTES: Estimates were regression-adjusted using ordinary least squares, controlling for pre-random assignment characteristics of sample members

Rounding may cause slight discrepancies in calculating sums and differences

Two-tailed t-tests were applied to differences between outcomes for the ERA group and the control group. Statistical significance levels are indicated as: ${ }^{*}=10$ per cent; ${ }^{* *}=5$ per cent; and ${ }^{* * *}=1$ per cent

Includes all customers randomly assigned between October 2003 and April 2005

aBenefits refers to Income Support for New Deal for Lone Parents customers, a combination of Income Support and Jobseeker's Allowance for Working Tax Credit customers, and Jobseeker's Allowance for New Deal 25 Plus customers 
There is no clear evidence that ERA boosted NDLP participants' employment retention rather than employment per se, or that it increased their progression in work over the course of the follow-up period (relative to the control group). However, it did encourage them to go into full-time work sooner than they might otherwise have done, which has always been a major part of successive governments' policies towards lone parents.

ERA caused a small reduction in NDLP participants' receipt of Income Support payments. Lone parents in the NDLP group all claimed Income Support at the time of random assignment. ERA reduced participants' number of months on Income Support within the first two follow-up years, but not thereafter (result not shown in table). ERA produced a longer-lasting effect on the amount of benefits participants received. Here, significant reductions were seen in each of follow-up years 1 through 3. Over all 5 years, those in the ERA group received almost $£ 500$ less in cumulative Income Support payments than those in the control group, a statistically significant reduction of five per cent relative to the control group average.

The subgroup analysis found that ERA had substantial and longer-lasting positive impacts on earnings for NDLP lone parents with higher educational qualifications (i.e., those with A-level or equivalent qualifications ${ }^{18}$ ) at the time they entered the programme. It increased their total average earnings over the four tax years 2005-2009 by about $£ 3,500$, a gain of 15 per cent over the control group average. At the same time, ERA had no earnings effects for those with lower qualifications. One interpretation of this finding is that lone parents who were unemployed but possessed better skills had more 'reserve capacity' to obtain and manage full-time work. ERA's incentives and support may have motivated and helped them make more effort to act on that capacity than they would have made on their own.

\subsubsection{ERA's economic impacts for the WTC group}

Of the three target groups, WTC lone parents (who were already employed part time when they entered ERA) most fully embraced ERA's advancement goals. In part, because of the way they were recruited to ERA-through a general community outreach effort rather than as part of the normal New Deal intake process within Jobcentre Plus - the WTC participants were a more selected, advantaged group than the NDLP and ND25+ target groups when they began the programme. Not only were they already working, they had better educational qualifications and, compared with the NDLP lone parents, were somewhat older and had older children. They joined ERA with the explicit intention of improving their current position in the labour market and were generally more receptive to advancement support and more interested in steady, full time work. This group was the most likely to receive ERA's retention bonuses.

Overall, ERA had no significant impact on the percentage of WTC participants who worked in any given month, but it increased their likelihood of working full time and their earnings. The earnings effect faded after their participation in the programme ended.

Figure 2 shows monthly employment rates for the WTC control group. Nearly all members of the control group worked at some point during the 5-year follow-up period, reflecting the fact that the tax credit is conditioned on working. (The true employment rate may have been somewhat higher; as previously noted, administrative records data do not capture all employment.) Furthermore, the proportion in work remained fairly stable at a fairly high rate, usually exceeding 60 per cent. Nonetheless, this rate is lower than the proportion ever in work during the follow-up period, indicating some movement in and out of the labour market even among this group. Because 


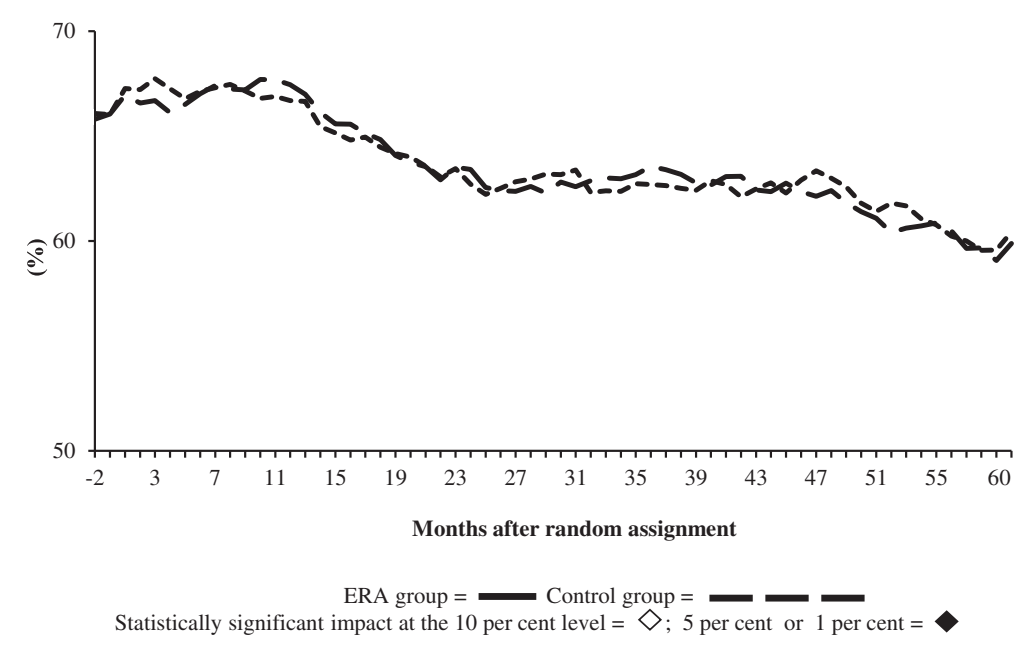

Fig. 2 ERA group and control group employment rate trends over the first 5 years after random assignment, Working Tax Credit target group. SOURCE: MDRC calculations from Work and Pensions Longitudinal Study employment records. NOTES: Rounding may cause slight discrepancies in calculating sums and differences. Two-tailed t-tests were applied to differences between outcomes for the ERA group and the control group. A white diamond on the axis indicates that the impact is statistically significant at the 10 per cent level. A black diamond on the axis indicates that the impact is statistically significant at the 5 per cent or 1 per cent level. These figures include some months before the time of random assignment. Months before random assignment are indicated with a negative sign

WTC participants were already employed at the time of random assignment, it was not expected that ERA would increase their likelihood of working during the follow-up period. More relevant was whether it would increase the consistency of their employment, their likelihood of working full time, and their advancement and earnings.

ERA's main effect for the WTC group was a short-term increase in earnings. As Table 6 shows, the programme increased earnings in the 2005-2006 tax year by an estimated $£ 402$, a statistically significant gain of about six per cent above the control group average. However, the earnings impacts were not statistically significant in later years, or for the follow-up period overall.

The short-term earnings gain was largely due to ERA participants working more hours. According to data from the 2-year customer survey, ERA increased the percentage of participants working full time by nearly 13 percentage points above the control group rate. However, this difference shrank to seven percentage points over time as the control group caught up, which may explain why the longer-term earnings impacts, though still positive, are not statistically significant.

ERA had no effects on the receipt of out-of-work benefits or in-work tax credits among the WTC group. At the time of random assignment, WTC participants were working 16 to $29 \mathrm{~h}$ a week and were not eligible to claim an out-of-work benefit, such as Income Support, at that time. Instead, they were receiving tax credit payments conditioned on work. Because ERA did not affect this group's employment rates or trends, it also had no effect on its receipt of benefits or tax credits.

\subsubsection{ERA's economic impacts for the ND25+ group}

The mostly male ND25+ group was generally the most disadvantaged and most difficult to engage of the three target groups ERA served. Given these challenges, it is 
noteworthy that ERA had larger and more sustained labour market impacts for the $\mathrm{ND25}+$ group than it did for the two lone parent groups.

ERA increased ND25+ participants' employment rates and earnings, and these positive effects persisted through the end of the study, suggesting that the ERA model can work for a highly disadvantaged population (see Table 6). ERA generated modest positive employment impacts for ND25+ participants in all five follow-up years, peaking at a statistically significant 3.6 percentage points during the second year, an increase of about 11 per cent relative to the control group average. Positive effects on employment continued even after participants' enrollment in the programme ended.

Figure 3 shows that there are positive impacts on employment for almost all of the months of the follow-up period, with about three-fifths of them being statistically significant. While the impacts faded somewhat late in year 3, they re-emerged in year 4 . Though the employment impacts are not statistically significant in the last couple of months of year 5, the balance of evidence still strongly suggests that ERA had a longrun impact on employment for the ND25+ group. Further analysis found that most of ERA's effect on employment among the ND25+ group was due to increases in movement into employment rather than increases in employment retention (Dorsett, 2014).

ERA's earnings impacts for this group are substantial and statistically significant in each year, totaling $£ 1,481$ over the four tax years for which earnings data are available. This represents a gain of 12 per cent above the control group average. In percentage terms, the earnings impacts are larger than the employment impacts, suggesting the possibility that there was also an impact on either hours of work, hourly wage rates, or

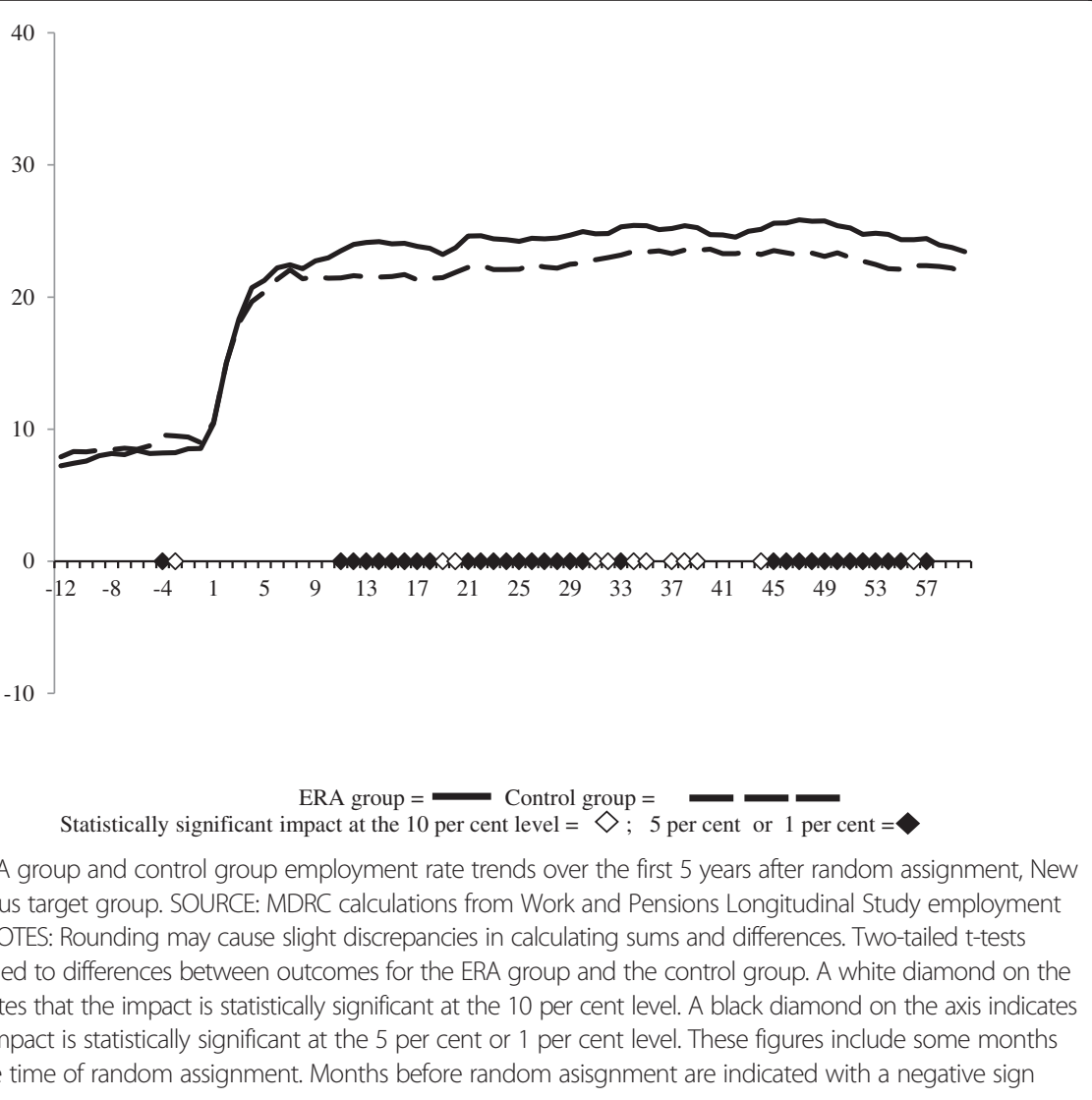


both. More recent evidence suggests that employment impacts lasted through the 2010-2011 tax year, though impacts on earnings faded to nonsignificance. ${ }^{19}$

The sustained impacts of ERA for the ND25+ group are especially noteworthy in light of the fact that this group was so severely disadvantaged and so difficult to employ normally, as suggested by outcomes for the control group. Only about one-third of ND25+ controls worked in any given year during the follow-up period, and just over half (55 per cent) had ever worked during that 5-year period. (In contrast, 79 per cent of the NDLP controls and 87 per cent of the WTC controls had worked at some point during the follow-up period. $)^{20}$ The fact that ERA was able to produce impacts for this long term unemployed group suggests that it may be possible to use financial incentives to promote reemployment of the long term unemployed to overcome any scarring effects of being out of the labour market, at least for some. This has important implications for several countries which are still struggling with long term unemployment and implies that the policies such as reemployment bonuses may be effective.

ERA reduced receipt of Jobseeker's Allowance among the ND25+ group. ND25+ participants had been receiving cash benefits in the form of Jobseeker's Allowance when they entered ERA. By the second year of follow-up, ERA had begun to reduce their reliance on that benefit. Over all five follow-up years, ERA reduced total average benefits received by a statistically significant $£ 426$ per ERA member, which is six per cent of the control group average.

\title{
4.2 The costs and benefits of ERA
}

The evaluation's cost-benefit analysis offers a way to summarise the net economic gains and losses that ERA produced, taking into account its combined effects on a wide variety of measures and the likely longer-term value of those effects after the end of the evaluation's 5 -year follow-up period. It considers gains and losses not only from the perspective of participants themselves, but also from the standpoint of the Exchequer (and, thus, taxpayers), which paid for the programme, and for society as a whole (which simply reflects the results for the other two perspectives combined). These results are show in Table 7.

\section{Box 1: Cost-Benefit Analysis Approach}

\author{
In brief, the following steps were used to conduct the cost-benefit analysis: \\ Step 1. The impact analysis was conducted to estimate most of the key benefits and costs, such as ERA's \\ impacts on earnings and on various benefit payments, including Income Support and Jobseeker's \\ Allowance payments, during the observation period. \\ Step 2. The impact estimates were used to populate a spreadsheet. \\ Step 3. The values in the spreadsheet were all converted to 2005-2006 lb using the Consumer Price \\ Index in order to adjust for inflation. \\ Step 4. As described in Section 7.4.2 of Hendra et al. (2011), formulas were applied to the impacts \\ estimates, especially the estimated impact on earnings, in order to determine some of the remaining \\ benefits and costs listed in the table-for example, ERA's effects on indirect taxes, National Insurance \\ Contributions, and pensions. \\ Step 5. Based on the estimated impacts during the last year of the observation period and the \\ assumed decay rates appearing in Hendra et al. (2011) the benefits and costs during the projection \\ period were predicted. These decay rates were based on the patterns in impacts over time. \\ Step 6. The benefits and costs were discounted to convert them to their value in the first year. \\ Step 7. The discounted benefit and cost values for each year during the time horizon were summed.
}


Table 7 Summary of ERA's cost-benefit results, by target group

\begin{tabular}{llll}
\hline \multirow{2}{*}{ Target group } & Net present value $(£)$ & & \\
\cline { 2 - 4 } New Deal for Lone Parents & -37 & Exchequer & -161 \\
Working Tax Credit & 230 & -124 & $-1,606$ \\
New Deal 25 Plus & 726 & $-1,836$ & 2,542 \\
\hline
\end{tabular}

SOURCES: MDRC calculations

NOTE: Benefits refers to Income Support for New Deal for Lone Parents customers, a combination of Income Support and Jobseeker's Allowance for Working Tax Credit customers, and Jobseeker's Allowance for New Deal 25 Plus customers

ERA was most cost-effective for the ND25+ group, producing a net economic gain for participants and a positive return on the government's investment. ERA markedly increased the net incomes of the ND25+ group. Using one set of assumptions to estimate cost-benefit results over a 10-year time period, the analysis found that participants' average net income increased by about $£ 725$ per participant. (This estimate is spread over all programme group members, whether or not they worked or received ERA services; those who were actually affected by ERA would, of course, have gained more.) ERA also returned a little over $£ 1,800$ to the Exchequer for every participant enrolled in the programme. This represents a return of $£ 4.01$ for every $£ 1$ it spent on ERA. The results from the overall perspective of society as a whole were positive as well. ${ }^{21}$

For the NDLP group, ERA had very small effects from all cost-benefit perspectives. On average, ERA resulted in a small loss in the net income of NDLP participants and small losses for the government's budget and society as a whole. However, a separate cost-benefit analysis for the NDLP subgroup with A-level and equivalent qualifications suggests that, for this subgroup, ERA increased the disposable income of participants while producing savings for the Exchequer. At the same time, the opposite effects are likely to have occurred as a result of ERA for NDLP participants with lower qualifications.

The net cost of operating ERA was greater for the WTC group than for the NDLP and ND25+ groups, but this greater expenditure did not yield a better return on the government's investment or substantial net income gains for participants. For the WTC group, ERA cost over twice as much per participant to operate than for the two New Deal groups. This is largely because the WTC group had a longer postemployment phase, which lasted the full 33 months of the programme. In contrast, the two New Deal groups received pre-employment services during the first nine months or so, which cost about the same as they did for the controls; in other words, the added cost of ERA for the first phase of the programme was almost negligible.

ERA appears to have modestly increased the disposable incomes of WTC participants. But because it was costly to operate, it produced a net loss for the Exchequer, and as a consequence, an overall loss from the societal perspective. ${ }^{22}$

\subsection{The relative importance of adviser support, incentives, and training}

The results of the UK ERA Demonstration have important bearing on key policy issues, including the relative importance of incentives, support, and training, the 
professionalization of the case manager role, and the overall benefits of the ERA approach to breaking the low pay, no pay cycle.

Both ERA's in-work support from advisers and its employment retention bonus may have contributed to the programme's positive labour market effects. All of the elements of ERA were offered as a package, and this makes it very difficult to determine whether some components of the intervention were more effective than others. For example, by design, participants were expected to speak with staff about advancement issues each time they received a retention bonus. However, the intensity with which local Jobcentre Plus offices implemented each of these components varied, and the local offices did not necessarily implement each component equally well.

In one attempt to shed light on the relative contributions to the programme's success of incentives versus in-work support, the evaluation included a non-experimental cross-office study using data on the NDLP sample. These results are summarised in Table $8 .{ }^{23}$ The table presents results for two outcomes, welfare receipt and employment status, during and after the programme was operating. ${ }^{24}$ As indicated in this table, several office characteristics were found to be associated with greater impacts of the ERA demonstration on the NDLP sample, both during and after the programme ended. ERA's main design feature was to extend the NDLP programme by providing help after employment was obtained. The cross-office analysis found that such retention services can lead to additional impacts beyond those obtained under the New Deal programme and can help individuals achieve economic self-sufficiency (by spending fewer months on welfare and more months employed). Offices that assigned more caseworkers to ERA participants tended to be more successful in reducing time spent on welfare. Offices that emphasised in-work advancement and in-work support more generally tended to deliver stronger effects of ERA as did those offices where awareness levels of the employment retention bonus were higher. On the other hand, offices that emphasised human capital investment tended to have weaker employment impacts.

The interquartile ranges of the impacts across offices are also presented in Table $8 .{ }^{25}$ These ranges are important because, in practice, few of the programme-control group differences in receiving the various services were very large, so the effect translates to modest variation across offices in the impact of the services. In interpreting the results of the cross-office study, it is important to understand that while certain office characteristics may be statistically significant in explaining programme impacts, lack of variation in these characteristics across offices may lead to only a small estimated variation in these impacts across offices. ${ }^{26}$ Thus, for example, while the results indicate the importance of conveying information about the financial rewards available to lone parent ERA participants who maintain employment, there was not much variation in the actual conveying of this information across offices, so it is associated with only modest variation in programme impacts across offices.

Table 8 shows that in offices where all of the advisers were working with ERA participants, the average programme group member spent 3 fewer months on welfare than in offices where no advisers were working with ERA participants. To put it another way, an individual in an office with a 10 percentage point higher proportion of advisers working with ERA participants will have .3 fewer months on welfare than an individual in an office where the same proportion of advisers worked with ERA participants and control group members (NDLP recipients). The information on interquartile ranges is 
Table 8 Effects of office characterisitics on office programme impacts over five years

\begin{tabular}{|c|c|c|c|}
\hline & Coefficient & Standard Error & $\begin{array}{l}\text { Interquartile Range } \\
\text { Across Offices }\end{array}$ \\
\hline \multicolumn{4}{|l|}{ Months on IS, years 1 to 3} \\
\hline Grand mean impact of ERA $\left(\beta_{0}\right)$ & $-1.52^{* * *}$ & 0.35 & -2.20 to -0.24 \\
\hline Proportion of advisers working with ERA customers & $-3.03^{*}$ & 1.62 & 0.30 to -0.25 \\
\hline Proportion of customers advised to think long-term & 0.17 & 2.12 & -0.02 to 0.02 \\
\hline $\begin{array}{l}\text { Proportion of customers receiving help finding education } \\
\text { course }\end{array}$ & 3.62 & 2.27 & -0.68 to 0.42 \\
\hline $\begin{array}{l}\text { Proportion of customers receiving help with in-work } \\
\text { advancement }\end{array}$ & -2.15 & 1.70 & 0.17 to -0.18 \\
\hline Proportion of customers receiving support while working & $-3.49^{* * *}$ & 1.02 & 0.60 to -0.51 \\
\hline Proportion of ERA customers aware of retention bonuses & $-9.42^{* * *}$ & 2.03 & 0.55 to -0.50 \\
\hline \multicolumn{4}{|l|}{ Months on IS, years 4 to 5} \\
\hline Grand mean impact of ERA $\left(\beta_{0}\right)$ & 0.04 & 0.06 & -0.92 to 0.84 \\
\hline Proportion of advisers working with ERA customers & $-2.50^{* *}$ & 1.05 & 0.25 to -0.21 \\
\hline Proportion of customers advised to think long-term & -0.23 & 1.83 & 0.03 to -0.03 \\
\hline $\begin{array}{l}\text { Proportion of customers receiving help finding education } \\
\text { course }\end{array}$ & 1.96 & 2.02 & -0.37 to 0.23 \\
\hline $\begin{array}{l}\text { Proportion of customers receiving help with in-work } \\
\text { advancement }\end{array}$ & 0.43 & 1.89 & -0.03 to 0.04 \\
\hline Proportion of customers receiving support while working & $-1.64^{*}$ & 0.90 & 0.28 to -0.24 \\
\hline Proportion of ERA customers aware of retention bonuses & $-6.43^{* * *}$ & 0.50 & 0.38 to -0.34 \\
\hline \multicolumn{4}{|l|}{ Months Employed, years 1 to 3} \\
\hline Grand mean impact of ERA $\left(\beta_{0}\right)$ & $0.76^{* *}$ & 0.03 & -0.63 to 2.12 \\
\hline Proportion of advisers working with ERA customers & 0.53 & 2.29 & -0.05 to 0.04 \\
\hline Proportion of customers advised to think long-term & -0.11 & 2.49 & 0.01 to -0.01 \\
\hline $\begin{array}{l}\text { Proportion of customers receiving help finding education } \\
\text { course }\end{array}$ & $-4.06^{* *}$ & 1.71 & 0.76 to -0.47 \\
\hline $\begin{array}{l}\text { Proportion of customers receiving help with in-work } \\
\text { advancement }\end{array}$ & $7.68^{* *}$ & 3.25 & -0.60 to 0.63 \\
\hline Proportion of customers receiving support while working & $3.23^{*}$ & 1.75 & -0.56 to 0.47 \\
\hline Proportion of ERA customers aware of retention bonuses & 8.41 & 7.58 & -0.49 to 0.45 \\
\hline \multicolumn{4}{|l|}{ Months Employed, years 4 to 5} \\
\hline Grand mean impact of ERA $\left(\beta_{0}\right)$ & 0.12 & 0.02 & -0.71 to 0.73 \\
\hline Proportion of advisers working with ERA customers & 1.79 & 1.56 & -0.18 to 0.15 \\
\hline Proportion of customers advised to think long-term & 1.09 & 1.67 & -0.13 to 0.12 \\
\hline $\begin{array}{l}\text { Proportion of customers receiving help finding education } \\
\text { course }\end{array}$ & $-2.33^{* *}$ & 1.06 & 0.44 to -0.27 \\
\hline $\begin{array}{l}\text { Proportion of customers receiving help with in-work } \\
\text { advancement }\end{array}$ & 1.67 & 1.52 & -0.13 to 0.14 \\
\hline Proportion of customers receiving support while working & $3.73^{* * *}$ & 1.17 & -0.64 to 0.54 \\
\hline Proportion of ERA customers aware of retention bonuses & 4.87 & 4.49 & -0.28 to 0.26 \\
\hline
\end{tabular}

Interquartile range is the predicted impact from the 25 th percentile of the office characteristic to the 75 th percentile *Significant at 10 per cent level; **Significant at 5 per cent level; *** Significant at 1 per cent level

very important because, in practice, few of the programme-control group differences in receiving this kind of help were very large, so the effect translates to only about a 6 month interquartile range across offices in the impact of the advisers on welfare receipt. 
In addition to understanding what services affect impacts, the results of the crossoffice analysis are also interesting in another regard. While the overall impact of ERA on welfare and employment status 4 to 5 years post-randomization was not statistically significant, the study finds that this masks significant variation of impacts across offices, some being positive and some negative. This suggests that, in addition to focusing on overall impacts, which is typically done in employment and training demonstrations, policy evaluation should, where possible, pay attention to implementation procedures across offices where the programme is being conducted. Rather than concluding a policy to be ineffective, the type of approach presented in the cross-office study may offer a means of learning from those with positive impacts in order to refine policy and, in time, raise overall effectiveness.

ERA increased participation in training courses, especially for the WTC target group. However, these impacts appear unrelated to ERA's effects on labour market outcomes. Analyses comparing ERA's impacts across target groups, subgroups, and offices suggest that any increase ERA caused in training did not lead to long-term earnings gains. For example, even though ERA increased participation in training for the NDLP group and, especially, the WTC group, it did not produce lasting earnings impacts for either of them. In addition, ERA's impacts on earnings were no larger for subgroups that experienced larger impacts on training than for those with smaller impacts or no impacts on training.

Figure 4 shows ERA's impacts on course-taking in years 1-2 and impacts on total 4-year earnings across the educational qualifications subgroups. The analysis focuses on training in the first 2 years in order to provide a sufficient amount of time for training to translate into advancement gains. It is reasonable to expect, however, that not all training courses are equally relevant for advancement. In particular, courses specific to occupations in which people currently work or to which they are hoping to transfer would be expected to lead more quickly to economic advancement. For the purposes of this analysis, courses were categorised as 'trade-specific' if they were relevant to specific occupations, such as nursing or business.

To facilitate the comparison of impacts, all impacts are expressed in 'percentage change' terms (to do this, the impact was divided by the control group level and multiplied by 100). The purpose of Fig. 4 is to measure whether impacts on training and qualifications correlate with impacts on earnings. For example, if subgroups that experienced a larger-than-average impact on training also had a largerthan-average impact on earnings, this would suggest that the additional training may have contributed to the larger earnings impacts. This analysis avoids problems with endogeneity by identifying subgroups defined at baseline (which are exogenous to the treatment) which had higher than average participation in training. However, an important caveat to this analysis is that ERA did more than incentivise and support training; thus, the contribution of other features of the programme cannot be ruled out. However, the absence of a correspondence between training impacts and earnings impacts would suggest that ERA's impacts on training did not pay off in the labour market or that labour market gains were achieved without increases in training.

Generally, Fig. 4 suggests that increasing course-taking alone did not lead to increases in earnings during the follow-up period. But neither did the acquisition of new 


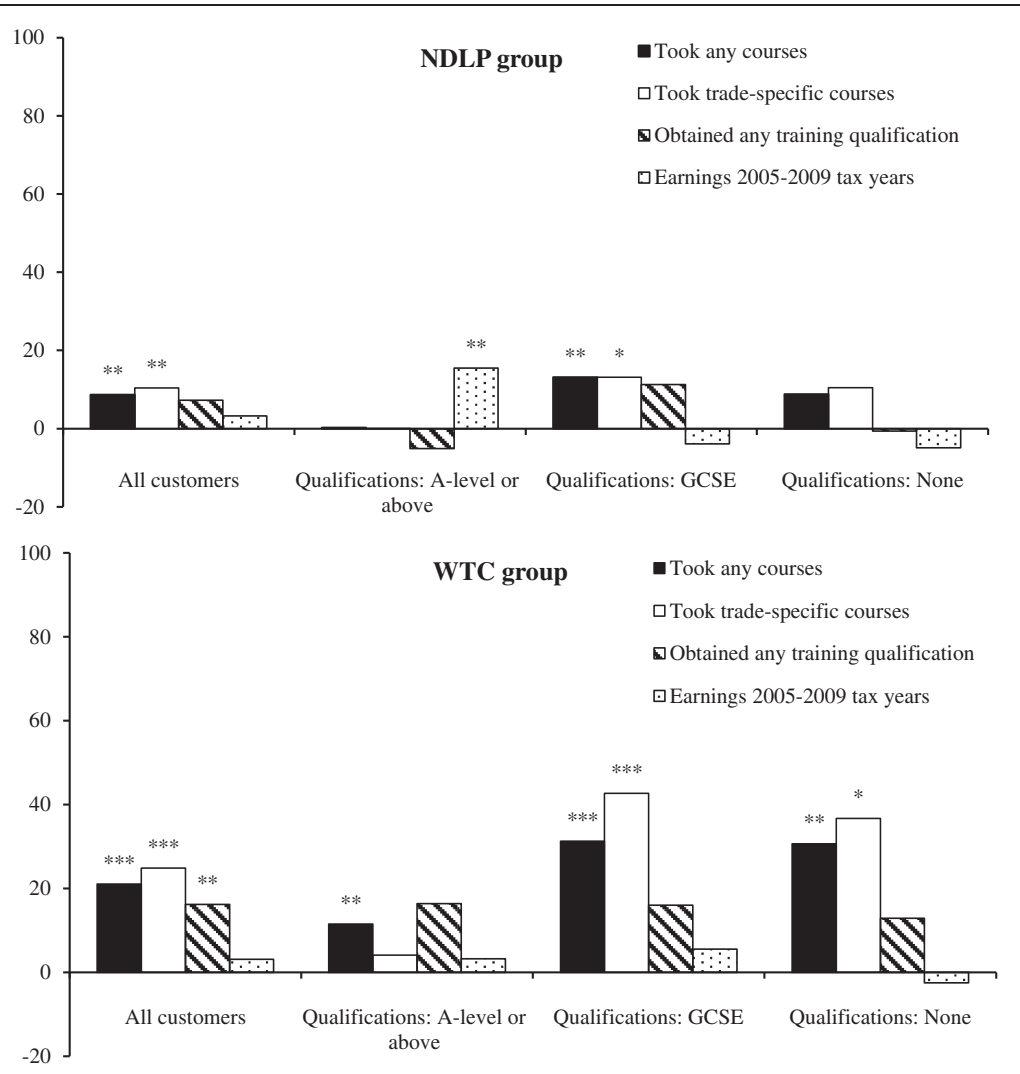

Fig. 4 Percentage change impacts of ERA on training during years 1-2, and cumulative earnings from 2005-2009 by baseline level of education subgroups. SOURCE: MDRC calculations from ERA 12- and 24-month customer surveys and Work and Pensions Longitudinal Survey earnings records. NOTE: To facilitate the comparison of impacts, all impacts in this figure are expressed in 'percentage change' terms. To do this, the impact was divided by the control group level and multiplied by 100 . Statistical significance levels are indicated as: ${ }^{*}=10$ per cent; ${ }^{* *}=5$ per cent; and ${ }^{* *}=1$ per cent

qualifications, such as training certificates, obtained by completing those courses. This is partly evident from the experiences of members of the NDLP subgroup who entered the programme with A-level qualifications. As discussed elsewhere, earnings impacts for this subgroup were more than 15 per cent above those of the control group, which is the largest increase among the subgroups shown in Fig. 4. However, those with Alevels did not experience increases in any of the education and training measures shown in the figure. A closer examination of the course-taking impacts for this subgroup reveals very few effects of ERA on any course-taking outcomes. Therefore, it seems likely that the impacts for this subgroup reflect the effectiveness of other ERA components, such as the employment retention bonus or adviser advancement support. This subgroup had relatively high take-up of the employment retention bonus, suggesting that the retention bonus was more important than the training support and training incentives, at least for this subgroup.

Results for NDLP participants who entered ERA with GCSEs also point to a lack of correspondence between increases in training and increases in earnings. This group experienced statistically significant impacts on taking any courses in general and in taking trade-specific courses, but no effect on longer-term earnings. A similar pattern is evident across the full WTC group, as well as each of the WTC subgroups, shown in 
Fig. 4. Every subgroup of WTC sample members shown in the figure experienced statistically significant increases in key training outcomes in years $1-2$. Some of the impacts on course-taking were quite large in percentage-change terms. For example, among WTC group members with GCSE qualifications, ERA increased trade-specific course-taking by over 40 per cent. Despite these large effects on course-taking, none of the subgroups experienced a statistically significant increase in earnings.

\section{Discussion}

ERA's pattern of results for lone parents, where earnings impacts emerge early on and then decline after the incentives ended, is broadly consistent with the pattern found for other programmes in the US and Canada that used financial incentives for similar populations. As mentioned in the introduction, several other randomised control trials in the US and Canada tested interventions that offered financial work incentives-either alone or in combination with job placement and other pre-employment services-to unemployed lone parents receiving cash benefits similar to Income Support. Although important exceptions exist, these programmes, like ERA, produced early positive impacts on employment and earnings but saw their impacts fade over time after the work incentives had ended (Michalopoulos, 2005).

While the results in ERA are broadly similar to other employment focused incentive programmes, they are somewhat weaker and faded somewhat earlier than many of the programmes. ${ }^{27}$ For illustration, ERA's labour market impacts for out of work lone parents are smaller than those produced by a fairly similar programme in the US. The most comparable programme to the UK ERA programme is an employment retention and advancement programme in the US state of Texas, which was evaluated as part of the US ERA demonstration and shared many similarities with the UK ERA model. It included pre-employment and post-employment support for unemployed lone parents and offered financial incentives for full-time work. The cash value of the Texas incentive was roughly comparable with ERA's retention bonus, although it was paid monthly rather than every four months. Like ERA, the Texas programme was tested with a random assignment design, and both the programme and control groups received preemployment services, such as those offered by the New Deal programme.

Two of the three pilot cities in the Texas study fully implemented the postemployment features of the model, and these two cities produced larger cumulative earnings gains than UK ERA generated for the NDLP group. Why the Texas programme's effects were larger is uncertain. One speculation is that this may be partly because in Texas, the size of the retention bonus relative to the local minimum wage and to the amount of benefits available to non-working lone parents was considerably greater than in Britain so that full-time work would 'pay' more. This may have increased the power of the Texas incentives to make a more enduring change in participants' labour market behaviour. Another possibility is that the higher minimum wage in the UK may have constrained labour market conditions, particularly for lower skilled women. This might explain why the effects were stronger for more educated participants (who likely earn more than the minimum wage). However evidence on the employment depressing effects of the minimum wage in the UK is unclear.

To be more effective, advancement-focused interventions like ERA may require advisers to have more expertise on industry-specific job opportunities, local knowledge, 
and training that is better aligned with those opportunities. ERA was a very different kind of programme for Jobcentre Plus. Consequently, its managers and line staff, who were expected to deliver an innovative advancement-focused intervention, faced a steep learning curve. In addition, they had to operate the intervention within a Jobcentre Plus environment that placed a high priority on job placement and offered little reward to staff for focusing on advancement-related outcomes for people who got jobs. However, as ERA advisers acquired more experience, they grew more adept and confident in helping employed participants develop and pursue advancement goals, such as moving up to better positions with their same employers, switching jobs, and finding training courses to improve their skills.

At the same time, ERA advisory staff functioned as employment 'generalists'. They offered participants general advice and guidance on adapting to work, encouraged them to consider seeking full-time work, helped them address issues of balancing work and family life, advised them on seeking promotions and finding better jobs, and urged them to enroll in training courses in whatever areas interested them. However, ERA advisers were not expected to have in-depth knowledge of particular occupations or industries or expertise on the career ladders and training requirements for jobs in those areas. Nor were they expected to steer participants assertively towards particular occupations known to offer real advancement opportunities. They were also not positioned to connect participants who had trained in particular occupational areas with relevant employers who were hiring people with the new skills those participants had acquired. These limitations might have undermined the benefits of the extra participation in training that ERA caused. Perhaps future advancement-focused programmes would be more effective if they included more career advice that is sector-specific and more narrowly focused on opportunities available in the local labour market.

The ERA findings by no means imply that training is irrelevant to advancement. However, they do suggest that other ways to try to ensure that training will have a pay-off in the labour market ought to be considered and carefully tested.

\section{Conclusions}

Employment retention and advancement remain difficult challenges for many lowincome people. ERA was designed to address those challenges, but its success was mixed. For some groups, ERA caused employment and earnings to increase more than they would have without the programme-in some cases, by a great deal-and it also yielded some positive cost-benefit results, both for participants and the Treasury. But for other groups, ERA did not improve participants' economic outcomes, and the government's budget incurred a net loss.

The evidence suggests that ERA's strategies, although uneven in their effects, clearly hold some promise. In particular, future efforts to promote employment retention and advancement should consider testing whether certain changes in the design and delivery of ERA's incentives and in-work support and in the types of skills required of advisers could help sustain and increase the programme's early impacts for unemployed and part-time employed lone parents (which faded after the programme ended). They could also increase the magnitude of the effects (which were sustained) for long-term unemployed men. In addition, ERA increased training completion for some groups 
without producing subsequent labour market gains, while it produced positive labour market effects for other groups without increasing training. This suggests that it is important to re-think how to deliver training that aims to promote advancement and improve incomes by building occupational skills.

\section{Endnotes}

${ }^{1}$ Income Support is an (almost) unconditional out-of-work benefit typically received by individuals who are not employed or are working fewer than $16 \mathrm{~h}$ a week. Entitlement for benefits depends on one's other income, and its value varies with family size and composition. It is roughly comparable to the Temporary Assistance for Needy Families programme in the US, although recipients are not required to look for work. When ERA began, lone parents with children under age 16 could receive Income Support and were not required to look for work; currently, only those with children under the age of seven are exempt from a work search requirement. Once their children reach age seven, non-employed lone parents who are capable of and available to work must actively seek employment and would receive Jobseeker's Allowance rather than Income Support.

${ }^{2}$ Jobseeker's Allowance is a conditional cash benefit available in Britain to unemployed individuals who are actively seeking work. Recent workers who built up entitlements while employed can receive contribution-based payments for six months, unaffected by other household income. The contributory portion of Jobseeker's Allowance is similar to the US unemployment insurance benefit. Other low-income people can receive Jobseeker's Allowance as a means-tested benefit and must be actively seeking work.

${ }^{3}$ The Department for Work and Pensions (DWP) oversaw the overall implementation and evaluation of the programme. A research consortium, headed by MDRC (headquartered in New York City), and including Britain's Policy Studies Institute, the Institute for Fiscal Studies, the National Institute of Economic and Social Research, and the Office for National Statistics, carried out the study. A subsidiary goal of the project was to help build capacity in Britain to conduct randomised trials of promising social innovations. This was accomplished through direct collaborative work between the US and British research partners and DWP, and also through broader US-UK learning exchanges involving practitioners and researchers.

${ }^{4}$ In 1997, the OECD set $30 \mathrm{~h}$ as the cut-off to delineate part-time and full-time work (Organisation for Economic Co-operation and Development, 1997). In ERA, part-time work is tied to Working Tax Credit eligibility rules, which set the threshold at a minimum of $16 \mathrm{~h}$ per week and specified that an extra amount is to be paid for work of 30 $\mathrm{h}$ or more per week.

${ }^{5}$ This provision was intended to accommodate the likelihood that many workers might lose jobs and offered an incentive for quick re-employment.

${ }^{6}$ At the currency exchange rate in effect on 11 February 2008, these retention bonus payments were equivalent to US\$780 and US\$4,680, respectively.

${ }^{7}$ Because of the voluntary nature of the experiment, many potential participants decided not to participate. The percentage of nonparticipants ranged from 23 to 30 per cent across the target groups. Chowdry \& Sienese (2011) explore what the impacts would have looked like had all eligibles participated in the experiment. They find that 
"Overall, the findings either validate the 4-year interim experimental results of the main ERA evaluation or indicate that the ERA intervention would have been even more effective for its full eligible population than it was for its actual participants."

${ }^{8}$ See Walker et al. (2006) for a discussion of the random assignment process.

${ }^{9}$ Although there were differences across the target groups, random assignment did achieve baseline equivalence of programme and control group characteristics within each target group.

${ }^{10}$ GCSEs are the main national qualification for 14 to 16 -year-olds taken in a range of academic and applied subjects. GCSEs constitute levels 1 or 2 on the National Qualifications Framework, depending on the grade achieved. GCSE's are a lower qualification than advanced levels ('A-levels'). A-levels are recognised as level 3 on the National Qualifications Framework. They are normally completed in years 12 and 13 of secondary school (age 17 to 19 years) and follow from GCSEs. They are the main route into higher education.

${ }^{11}$ For the ND25+ group, only two survey waves, at 12 and 24 months, were conducted.

${ }^{12}$ As discussed in more detail in the final ERA report, the survey results are used cautiously due to concerns about response bias, particularly for the last wave of the survey (Hendra et al. 2011).

${ }^{13}$ The regression model consisted of exogenous characteristics chosen based on expected fit with the key employment and earnings outcomes. The covariates were all measured at baseline and (because of random assignment) are orthogonal to treatment group status. Covariates included prior work and barriers to working, race, region, education, and a range of demographic variables.

${ }^{14}$ Further analysis found that despite the improvements in the programme over time, the impacts of ERA did not vary by cohort for the two lone parent groups. There is only limited evidence of strengthening in the ND25+ target group.

${ }^{15}$ This analysis is nonexperimental because it is only among those who worked. Therefore, these results could be confounded by bias via selection into work.

${ }^{16}$ Earnings data from the 2004-2005 tax year were not used because, for some sample members, that tax year included some months before the start of the study.

${ }^{17}$ Tests for the difference in these impact estimates were not conducted, though it is unlikely that the impacts on employment and earnings were statistically different from each other.

${ }^{18} \mathrm{~A}$-level qualifications indicate that a person passed a series of advanced secondary school examinations usually taken around age 18 or recognised equivalents that often involve a more vocational element.

${ }^{19}$ Further analysis analysed impacts in the 2010-2011 tax year. For the two lone parent target groups, results were similar to the 2009-2010 tax year (no statistically significant impacts on employment or earnings). For the ND25+ target group, the estimated impacts on earnings faded slightly to nonsignificance, but the impacts on employment were still statistically significant (1.91 percentage points*)

${ }^{20}$ Further analysis found that impacts were concentrated among social housing residents, though the difference across subgroups was not statistically significant.

${ }^{21}$ The overall pattern of cost-benefit results holds up in the face of various sensitivity checks using different assumptions, including shorter and longer time horizons. 
${ }^{22}$ As is almost always the case, several nonfinancial benefits and costs of the programme are likely undercounted. However the analysis did try to monetise several benefits such as effects on health and quality of life.

${ }^{23}$ The full analysis is presented in Richard Dorsett and Philip K. Robins, "A MultiLevel Analysis of the Impacts of the UK Employment Retention and Advancement Demonstration, Evaluation Review, 37 (2), April 2013, pp. 63-108.

${ }^{24}$ Earnings were also studied, and the results were qualitatively similar to those for employment status.

${ }^{25}$ The interquartile range of programme impacts is the range between the $25^{\text {th }}$ and $75^{\text {th }}$ percentile of predicted impacts across offices.

${ }^{26}$ In their work on enterprise zones in the US, Kolko and Neumark (2010) make a similar argument about the importance of analysing variation in implementation when trying to understand the effects of public policy. In their work they find that enterprise zones are more effective in locations where managers more aggressively market the zones and where there is a lower share of manufacturing.

${ }^{27}$ While the UK ERA results are somewhat weaker than other financial incentive programmes, they are consistent with other employment programmes for low wage workers. Hendra \& Hamilton, (2015 forthcoming) provide a review of various programmes focused on unemployed/employed low wage workers. Within that set of programmes, the UK ERA results are broadly similar to many welfare-to-work programmes. Most of these programmes had positive estimated impacts that faded over time. Compared to other postemployment services programmes (such as those studied in the Post Employment Services Demonstration or the US Employment Retention and Advancement project), the UK ERA results are more positive: many of those programmes had no estimated impacts on employment or earnings (Rangaran et al., 1999 \& Hendra et al., 2010). For another more comprehensive review of active labour market programmes, see Card et al. (2010).

\section{Appendix}

List of Papers and Reports Related to UK ERA

The effect of temporary in-work support on employment retention: evidence from a field experiment. 2014. Richard Dorsett.

A Multilevel Analysis of the Impacts of Services Provided by the UK Employment Retention and Advancement Demonstration. 2013. Richard Dorsett and Philip K. Robins.

Breaking the Low-Pay, No-Pay Cycle Final Evidence from the UK Employment Retention and Advancement (ERA)Demonstration. 2011. Richard Hendra, James A. Riccio, Richard Dorsett, David H. Greenberg, Genevieve Knight, Joan Phillips, Philip K. Robins, Sandra Vegeris, Johanna Walter

Non-participation in the Employment Retention and Advancement Study: Implications for the experimental fourth-year impact estimates.. 2011. Chowdry, H. and Sianesi, B.

Employment Retention and Advancement (ERA) Demonstration Delivery, Take-Up, and Outcomes of In-Work Training Support for Lone Parents. 2011. Richard Hendra, Kathryn Ray, Sandra Vegeris, Debra Havenstone, Maria Hudson

Different Settings, Common Strategy Using Earnings Supplements to Improve Employment Retention and Advancement Programs in Texas and the United Kingdom. 2010. Erika Lundquist, Tatiana Homonoff 
The Cost of Services and Incentives in the UK Employment Retention and Advancement (ERA) Demonstration. 2009. David H. Greenberg, Johanna Walter, Genevieve Knight Implementation and Second-Year Impacts for New Deal 25 Plus Customers in the UK Employment Retention and Advancement (ERA) Demonstration. 2008. Cynthia Miller, Helen Bewley, Verity Campbell-Barr, Richard Dorsett, Gayle Hamilton, Lesley Hoggart, Tatiana Homonoff, Alan Marsh, Kathryn Ray, James A. Riccio, Sandra Vegeris

Implementation and Second-Year Impacts for Lone Parents in the UK Employment Retention and Advancement (ERA) Demonstration. 2008. James A. Riccio, Helen Bewley, Verity Campbell-Barr, Richard Dorsett, Gayle Hamilton, Lesley Hoggart, Alan Marsh, Cynthia Miller, Kathryn Ray, Sandra Vegeris

Implementation and First-Year Impacts of the UK Employment Retention and Advancement (ERA) Demonstration. 2007. Richard Dorsett, Verity Campbell-Barr, Gayle Hamilton, Lesley Hoggart, Alan Marsh, Cynthia Miller, Joan Phillips, Kathryn Ray, James A. Riccio, Sarah Rich, Sandra Vegeris

Staying in Work and Moving Up Evidence from the UK Employment Retention and Advancement Demonstration. 2006. Lesley Hoggart, Verity Campbell-Barr, Kathryn Ray, Sandra Vegeris

Making Random Assignment Happen Evidence from the UK Employment Retention and Advancement (ERA) Demonstration. 2006. Robert Walker, Lesley Hoggart, Gayle Hamilton

Competing interests

The IZA Journal of Labor Policy is committed to the IZA Guiding Principles of Research Integrity. The authors declare that they have observed these principles.

\section{Acknowledgement}

This paper draws heavily on the work of the following authors who produced the final report of the United Kingdom Employment Retention and Advancement Report (Hendra et al., 2011): Richard Hendra, James A. Riccio, Richard Dorsett, David H. Greenberg, Genevieve Knight, Joan Phillips, Philip K. Robins, Sandra Vegeris, Johanna Walter, with Aaron Hill, Kathryn Ray, and Jared Smith. Earlier reports are drawn on as well. All papers and reports produced as part of the ERA evaluation are listed in the Appendix.

Particular thanks are due to all members of the research samples who consented to be part of the study, many of whom also participated in the customer surveys; to the Jobcentre Plus staff who shared their experiences in implementing and delivering the Employment Retention and Advancement (ERA) programme; and to the Technical Advisers for their help in facilitating the research and for their own participation in interviews. Technical advisors were posted in each ERA district, and ensured that ERA services were delivered in accordance with the policy design and provided general support for the evaluation effort. At the Department for Work and Pensions (DWP), we would like to thank the ERA Project Team and the DWP Evaluation Team, including Tom Andrews, Ingun Borg, Mike Daly, Christine Daniels, Leroy Groves, and Sally Marshall and their predecessors including John Stafford, Jane Hall, Ellenor Brooks, and Aisha Riaz. In addition, we want to thank the ERA Evaluation Steering Group and Alan Marsh for their review of the work which was summarized in this paper.

At the Policy Studies Institute, we would like to acknowledge the contributions of other members of the ERA research team: Wendy Duldig, Lesley Hoggart, Sue Kirkpatrick, Karen Mackinnon, Christine Bertram, Andrew Dunn, and Rebecca Taylor. The project administrators were Mehrdad Hashemi-Sadrai, Jenny Lau, and Hilary Salter. At MDRC, our thanks go to Cynthia Miller who provided insightful comments on previous drafts of the paper. Thanks also to Daniel Gallagher for research assistance.

We would also like to thank Professor David Neumark and anonymous referee.

Responsible editor: David Neumark

Author details

${ }^{1}$ MDRC, New York, USA. ${ }^{2}$ National Institute of Economic and Social Research, London, UK. ${ }^{3}$ Department of Economics, University of Miami, Miami, FL, USA.

Received: 3 January 2015 Accepted: 3 June 2015

Published online: 24 July 2015

References

Arulampalam W (2001) Is unemployment really scarring? Effects of unemployment experiences on wages. Econ J Royal Econ Soc 111(475):585-606

Blank RM, Card D, Robins PK (1999). Financial incentives for increasing work and income among low-income families (No. w6998). National Bureau of Economic Research.

Blundell R, Etheridge B (2010) Consumption, income and earnings inequality in Britain. Rev Econ Dynam 13(1):76-102 
Cappellari L, Jenkins S (2014) Earnings and labour market volatility in Britain, with a transatlantic comparison. Lab Econ 30:201-211

Card D, Kluve J, Weber A (2010) Active labour market policy evaluations: a meta-analysis*. Econ J 120(548):452-F477

Chowdry H, Sianesi B (2011) Non-Participation in the Employment Retention and Advancement Study: Implications for the Experimental Fourth-Year Impact Estimates. Department for Work and Pensions Working Paper No 96. Department for Work and Pensions, Sheffield

Dex S, Smith C (2001) Employee Commitment as an Outcome of Family-friendly Policies?: Analysis of the Workplace Employee Relations Survey. Research Papers in Management Studies- University of Cambridge Judge Institute of Management Studies WP

Dickens R (unpublished 2000a) The Low Pay - No Pay Cycle: A Report for the Welfare to Work Team. HM Treasury. Centre for Economic Performance, London School of Economics, London

Dickens R (2000b) Caught in a trap? Wage mobility in Britain: 1975-1994. Economica 67:477-497

Dorsett R (2014) The effect of temporary in-work support on employment retention: evidence from a field experiment. Lab Econ 31:61-71

Dorsett R, Robins PK (2013) A multilevel analysis of the impacts of services provided by the UK employment retention and advancement demonstration. Eval Rev 37(2):63-108

Elsby MW, Hobijn B, Sahin A (2010) The Labor Market in the Great Recession (No. w15979). National Bureau of Economic Research

Hendra R, Dillman KN, Hamilton G, Lundquist E, Martinson K, Wavelet M, Williams S (2010) How Effective are Different Approaches Aiming to Increase Employment Retention and Advancement. MDRC, New York

Hendra R, Riccio JA, Dorsett R, Greenberg DH, Knight G, Phillips J, Robins PK, Vegeris S, Walter J, Hill A, Ray K, Smith J (2011) Breaking the Low-Pay, No-Pay Cycle: Final Evidence from the UK Employment Retention and Advancement (ERA) Demonstration. Research Report No. 765. UK Department of Works and Pensions, Sheffield

Hendra, R. and Hamilton G. (2015-Forthcoming). Improving the Effectiveness of Education and Training Programs for Low-Income Individuals Building Knowledge from Three Decades of Rigorous Experiments. In Transforming U.S. Workforce Development Policies for the 21st Century. Kalamazoo: W.E. Upjohn Institute for Employment Research.

Hershey A, Pavetti D (1997) Turning Job Finders into Job Keepers. Welfare to Work Vol 7 (1)

Kolko J, Neumark D (2010) Do some enterprise zones create jobs? J Policy Anal Manage 29(1):5-38

Kroft K, Lange F, Notowidigdo M (2013) Duration dependence and labor market conditions: evidence from a field experiment. Q J Econ 128(3):1123-1167

Martinson K, Hamilton G (2011) Providing Earnings Supplements to Encourage and Sustain Employment: Lessons from Research and Practice. MDRC, New York

Michalopoulos C (2005) Does Making Work Pay Still Pay? An Update on the Effects of Four Earnings Supplement Programs on Employment, Earnings, and Income. MDRC, New York

Michalopoulos C, Robins PK, Card D (2005) When financial work incentives pay for themselves: evidence from a randomized social experiment for welfare recipients. J Publ Econ 89(1):5-29

Nunn A, Johnson S, Kelsey S, Usher D (2007) Job Outcome Target National Evaluation, Department for Work and Pensions Research Report No 462. Corporate Document Services, Leeds

Rangaran, A. and Novak, T. (1999) The struggle to sustain employment: The effectiveness of the Postemployment Services Demonstration, Princeton, NJ: Mathematica Policy Research.

Robins PK, Michalopoulos C, Foley K (2008) Are two carrots better than one? The effects of adding employment services to financial incentive programs for welfare recipients. Ind Labor Relat Rev 61(3):410-423

Stewart, M. (2007) 'The inter-related dynamics of unemployment and low-wage employment', Journal of Applied Econometrics 22: 511-531.

Stewart M, Swaffield J (1999) Low pay dynamics and transition probabilities. Economica 66:23-42

Walker, R, Hoggart, L, and Hamilton, G (2006) Making random assignment happen: Evidence from the UK Employment Retention and Advancement (ERA) demonstration. Department for Work and Pensions Research Report No 330, Leeds: Corporate Document Services.

\section{Submit your manuscript to a SpringerOpen ${ }^{\oplus}$ journal and benefit from:}

- Convenient online submission

- Rigorous peer review

- Immediate publication on acceptance

- Open access: articles freely available online

- High visibility within the field

- Retaining the copyright to your article 